OPEN ACCESS

Edited by:

Amit V. Pandey,

University of Bern, Switzerland

Reviewed by:

Volker Martin Lauschke, Karolinska Institutet (KI), Sweden Balraj Mittal,

British Burn Association, United Kingdom Maja Krajinovic,

Université de Montréal, Canada

*Correspondence:

Emma C. Bernsen

e.c.bernsen@

prinsesmaximacentrum.nl

Specialty section:

This article was submitted to

Pharmacogenetics and Pharmacogenomics,

a section of the journal

Frontiers in Pharmacology

Received: 03 March 2020

Accepted: 21 July 2020

Published: 05 August 2020

Citation:

Bernsen EC, Hagleitner MM, Kouwenberg TW and Hanff LM (2020) Pharmacogenomics as a Tool to Limit Acute and Long-Term Adverse Effects of Chemotherapeutics: An Update in

Pediatric Oncology.

Front. Pharmacol. 11:1184. doi: 10.3389/fphar.2020.01184

\section{Pharmacogenomics as a Tool to Limit Acute and Long-Term Adverse Effects of Chemotherapeutics: An Update in Pediatric Oncology}

\author{
Emma C. Bernsen ${ }^{1 *}$, Melanie M. Hagleitner ${ }^{2}$, Theodorus W. Kouwenberg ${ }^{2}$ \\ and Lidwien M. Hanff ${ }^{1}$ \\ 1 Pharmacy, Princess Máxima Centre for Pediatric Oncology, Utrecht, Netherlands, ${ }^{2}$ Department of Pediatric Hemato-
oncology, Princess Máxima Centre for Pediatric Oncology, Utrecht, Netherlands
}

In the past decades, new cancer treatments have been introduced in pediatric oncology leading to improvement in clinical outcomes and survival rates. However, due to interindividual differences, some children experience severe chemotherapy-induced toxicities or a poor clinical outcome. An explanation for the diversity in response to chemotherapy is genetic variation, leading to differences in expression and activity of metabolizing and transport enzymes as well as drug targets. Pharmacogenetic testing has emerged as a promising tool to predict and limit acute and long-term adverse effects in patients. However, in pediatric oncology, limited number of patients and a considerable diversity in study results complicate the interpretation of test results and its clinical relevance. With this review, we provide an overview of new developments over the past four years regarding relevant polymorphisms related to toxicity in pediatric oncology. The following chemotherapeutics and associated toxicities are discussed: alkylating agents, anthracyclines, asparaginase, methotrexate, platinum compounds, steroids, thiopurines, topoisomerase inhibitors, and vinca alkaloids. Our review identifies several questions regarding the role of genetic variants in chemotherapyinduced toxicities. Ambiguities in the literature stem from small population sizes, differences in (statistical) interpretation and variations in sequencing technologies as well as different clinical outcome definitions. Standardization of clinical outcome data and toxicity definitions within electronic health records combined with the increased availability of genomic sequence techniques in clinical practice will help to validate these models in upcoming years.

Keywords: pediatric oncology, chemotherapeutic agents, drug toxicity, adverse effects, pharmacogenomics

\section{INTRODUCTION}

Over the past decades, the 5-year survival rate for childhood cancer improved from $58 \%$ for children diagnosed during 1975 to 1977 to $83 \%$ for those diagnosed during 2005 to 2015 (O'Leary et al., 2008; Pui et al., 2011; Siegel et al., 2019). This improvement is mainly driven by risk stratification and intensification of cytotoxic chemotherapy. As survival is increasing, the focus has shifted to decreasing serious toxicities of chemotherapy without losing anti-tumor effectiveness of 
multimodality treatment. Inter-individual differences in drug response have been implicated as an important consequence of chemotherapy-induced toxicities (Roden et al., 2019). As a result, genetic predisposition has been proposed as an explanation for individual variation in chemotherapeutic response and toxicity.

Pharmacogenomics includes all studies assessing genetic variations in patients influencing pharmacokinetics (drug absorption, metabolism, excretion, cellular transport) and pharmacodynamics. Pharmacogenetic testing has emerged as a promising tool to predict and limit acute and long term adverse effects in individual patients, and is widely investigated in pharmacogenomics (PGx) and genome-wide association studies (GWAS) (Relling et al., 2020). At present, the Clinical Pharmacogenetics Implementation Consortium (CPIC) has provided guidelines for the implementation of pharmacogenetics in practice, which led to 23 clinical guidelines, comprising 19 genes and 46 drugs (Haidar et al., 2019; Relling et al., 2020). In the Netherlands, The Dutch Pharmacogenetics Working Group (DPWG) has reviewed 97 gene-drug interactions, leading to multiple recommendations for clinical practice (KNMP apothekersorganisatie; van der Wouden et al., 2019). However, these guidelines are predominantly based on research in adults and exclude some pediatric cancer treatment drugs (e.g. asparaginase).

The rarity of childhood cancer and inherently small patient populations combined with diversity in outcome measurements led to uncertainties regarding the clinical relevance of genetic testing in pediatric oncology as well as difficulties with the interpretation of test results (Relling and Klein, 2011). Given that high survival rate in pediatric cancer is dependent on intensive chemotherapy, clinicians are hesitant to preemptively reduce dosages due to genetic variants, as retaining the beneficial outcome is of utmost importance in pediatric cancer.

The availability and affordability of genomic technologies have improved greatly in the past years, resulting in many studies, albeit of varying quality. In this literature review we provide an overview of developments and new insights over the last years regarding relevant genes and polymorphisms as well as their role in acute and long-term adverse effects of drugs in pediatric oncology. The review is limited to pediatric age group (0-18 years). To address the recent developments, we reviewed recent publications (from 2016 onward) using terms related to pediatric oncology, pharmacogenomics and pharmacogenetics, and toxicities of (pediatric) cancer drugs. While a wide variety of supportive care drugs (e.g. anti-infective drugs, analgesics drugs, and antiemetic drugs) and immunotherapy are also used in pediatric oncology, we focus exclusively on the association between genetic variants and chemotherapy-induced toxicities.

\section{ROLE OF PHARMACOGENETIC VARIATIONS IN CHEMOTHERAPEUTIC RELATED TOXICITIES}

The following chemotherapeutics and their toxicities have been selected based upon extensive use in pediatric oncology: alkylating agents, anthracyclines, asparaginase, methotrexate, platinum compounds, steroids, thiopurines, topo-isomerase inhibitors, and vinca alkaloids. For each chemotherapeutic agent, the relationship between various genetic variations and chemotherapy-induced toxicity are discussed. An overview of recent studies included in this review can be found in Supplementary Table 1.

\section{Alkylating Agents}

Alkylating agents are widely used antitumor prodrugs deriving their cytotoxic effect from adding an alkyl group to the guanine base of the DNA molecule. This alkylation results in abnormal nucleotide sequences, miscoding of messenger RNA, blockade of DNA replication and breakage of DNA strands and eventually tumor cell death. Most common alkylating agents in pediatric oncology are nitrogen mustards like cyclophosphamide and ifosfamide, alkyl sulfonates like busulfan and triazenes such as dacarbazine and temozolomide. Alkylating agents show a wide range of toxicity including myelosuppression, kidney and gastrointestinal toxicities. Due to limited data, only cyclophosphamide, ifosfamide, and busulfan are updated in this review. In addition to toxicity studies, we also included studies analyzing the association between pharmacokinetics of alkylating agents and genetic variants, while limited studies were available which directly investigated the association between genetic variants and alkylating-induced toxicities.

\section{Cyclophosphamide \\ Metabolism and Transport}

Activation of cyclophosphamide is catalysed by the hepatic cytochrome P450 (CYP) isozymes CYP2B6, CYP2C19, and CYP3A4. The overall metabolism of cyclophosphamide is complex, with numerous enzymes involved which vary in expression and activity.

\section{Genetic Variances and Toxicity}

In the past, CYP2B6 and CYP2C19 have shown to influence cyclophosphamide pharmacokinetics in adult patients (Helsby et al., 2010). Recently, the influence of CYP2B6 on cyclophosphamide clearance was confirmed in the pediatric population of 49 B-cell Non Hodgkin Lymphoma (NHL) patients. Patients carrying $C Y P 2 B 6^{*} 6$ had significant lower cyclophosphamide clearance (Veal et al., 2016). This is in line with previous research showing a decreased function of $C Y P 2 B 6^{\star} 6$ (Lang et al., 2001; Hesse et al., 2004; Zukunft et al., 2005; CYP2B6 P, 2020).

\section{Ifosfamide}

\section{Metabolism and Transport}

Ifosfamide requires activation by $C Y P 3 A 4$ and $C Y P 2 B 6$ to active metabolites. Variation in the renal expression of $C Y P 2 B 6$ leads to higher rates of ifosfamide metabolite chloroacetaldehyde (CAA), which is nephrotoxic. Increasing evidence suggests that CAA is also involved in ifosfamide-induced encephalopathy.

Genetic Variances and Toxicity

Very limited data is available regarding the influence of genetic variants on toxicity of ifosfamide. $\mathrm{CYP} 2 B 6^{*} 6$ carriers have been 
linked with ifosfamide-induced encephalopathy in a report of three pediatric cases (Duflot et al., 2018). Earlier, this genotype has been linked with lower catalytic activity and protein expression in the liver, higher concentrations of ifosfamide and higher rates of CAA associated toxicity (Wang and Tompkins, 2008). This could be a mechanism for ifosfamide-induced encephalopathy, though more extensive studies are needed to confirm this assumption.

In conclusion, prospective studies are needed to further elucidate the role of CYP2B6 polymorphism in the metabolism and toxicity of cyclophosphamide and ifosfamide.

\section{Busulfan}

\section{Metabolism and Transport}

Busulfan, widely used in conditioning regimens before hematopoietic stem cell transplantation, has a narrow therapeutic window and demonstrates wide interpatient variability in pharmacokinetics. High drug exposure is associated with increased risk of toxicities, such as veno-occlusive disease, while low drug exposure is associated with treatment failure. Busulfan is metabolized in the liver by glutathione S-transferase isoenzymes (GSTs). GSTA1 is the predominant GST isoenzyme in the metabolism of busulfan. GSTM1 and GSTT1 are involved to a lesser extent.

\section{Genetic Variances and Toxicity}

In the past, several studies in adult and pediatric patients showed a higher busulfan clearance in patients with $G S T A{ }^{*} A{ }^{*} A$ genotype (with consequent lower AUC), while patients with $G S T^{\star} B /{ }^{*} B$ genotype had lower clearance (with consequent higher AUC) (Myers et al., 2017). While this association has been found, it is noteworthy that not all studies found clinical correlations. Recently, one study has successfully incorporated GSTA1 genotype into a pharmacokinetic model for busulfan in a group of 112 pediatric patients. In this study, GSTA1 ${ }^{\star} A 2$ or ${ }^{\star} A 3$ homozygote or heterozygote carriers showed a $7 \%$ higher clearance. Also, clearance of patients carrying $G S T A 1^{\star} B 1 b^{\star} B 1 b$ was $12 \%$ lower. Based doses in this study resulted in a better achievement of AUC targets (see Supplemental Material of Nava et al. for gene expression information) (Nava et al., 2018). However, another recent study showed no significant association with GST polymorphisms and busulfan pharmacokinetics (Nishikawa et al., 2019). These contradictory data may be attributed due to small study cohorts and variation in study design. Further basic research and clinical investigative efforts are required to fully understand the key factors determining busulfan PGx characteristics (Myers et al., 2017).

\section{Anthracyclines}

Anthracyclines are widely used in many pediatric cancers, including leukemia, lymphomas, and solid tumors. Anthracyclines agents are doxorubicin, daunorubicin, idarubicin, epirubicin, and mitoxantrone. While their mechanism of action is not fully known, it is believed anthracyclines interfere with DNA metabolism (including inhibition of topoisomerase II) and damage DNA through reactive oxygen species (ROS)
(McGowan et al., 2017; Anthracyclines and related substances, 2020). Notorious for their severe cardiotoxicity, anthracycline cumulative doses are monitored closely during treatment.

\section{Anthracycline-Induced Cardiotoxicity}

Anthracycline-induced cardiotoxicity can be acute and reversible (within the first weeks of treatment) or develops one or more year(s) after treatment discontinuation and causes chronic cardiotoxicity. There are various theories with regard to the development of anthracycline-induced cardiotoxicity. One theory discusses the formation of ROS and topoisomerase II alterations which causes damage to cardiomyocytes and mitochondria in cells. ROS is mainly formed during anthracyclines metabolism. Also, risk factors such as sex, age, comorbidities, and cumulative dose of anthracyclines (>350 mg/ $\mathrm{m}^{2}$ ) play a relevant role in anthracycline-induced cardiotoxicity (see for more in-depth information on cardiotoxicity Bansal et al.'s review) (Bansal et al., 2017). However, ROS formation, topoisomerase II alterations and the mentioned risk factors do not fully explain the inter-individuals differences in the severity of cardiotoxicity among children (Huang et al., 2017). This led to the assumption that genes involved in metabolism and transport of anthracyclines as well as genes associated with the prevention of ROS and genes involved in iron homeostasis could also influence anthracycline-induced cardiotoxicity (see Figures 1 and 2) (Thorn et al., 2011; Aminkeng et al., 2016; Doxorubicin Pathway, 2020; Doxorubicin Pathway (Cardiomyocyte Cell) P, 2020).

\section{Metabolism and Transport}

Anthracyclines are metabolized through three pathways: hydroxylation, semiquinone formation, and/or deoxyaglycone formation. Hydroxylation is mediated by NADPH-dependent carbonyl $(C B R)$ and aldo-keto $(A K R)$ reductases. Enzymes known for catalyzing semiquinone formation are CYP reductase $(C Y P R), \mathrm{NADH}$ dehydrogenase (NDUFS), nitric oxide synthase (NOS), and xanthine oxidase. These conversions also increase the formation of reactive oxygen species (ROS). The final metabolizing step is deoxyaglycone formation. This is catalyzed by NADPH quinone oxidoreductases (NQO1), CPR, and xanthine dehydrogenase $(X D H)$ (see Figures 1 and 2) (Thorn et al., 2011; Edwardson et al., 2015; Doxorubicin Pathway, 2020; Doxorubicin Pathway (Cardiomyocyte Cell) P, 2020).

While the transport of anthracyclines is not fully known, acknowledged genes involved in transport of anthracyclines are ATP-binding cassette $(A B C) A B C B 1, A B C C 1, A B C C 2, A B C G 2$, and solute carrier (SLC) SLC22A16 (see Figures 1 and 2).

\section{Genetic Variants in Metabolizing and Transport Enzymes}

Past studies showed a strong association between genetic variations SLC28A3 (rs7853758 and rs885004) and detoxifying uridine diphosphate glucuronosyl transferase (UGT) UGT1A6*4 (rs17863783) and anthracycline-induced cardiotoxicity (Visscher et al., 2013; Aminkeng et al., 2016). Also genetic variations in CBR3 (Blanco et al., 2012; Visscher et al., 2012), 


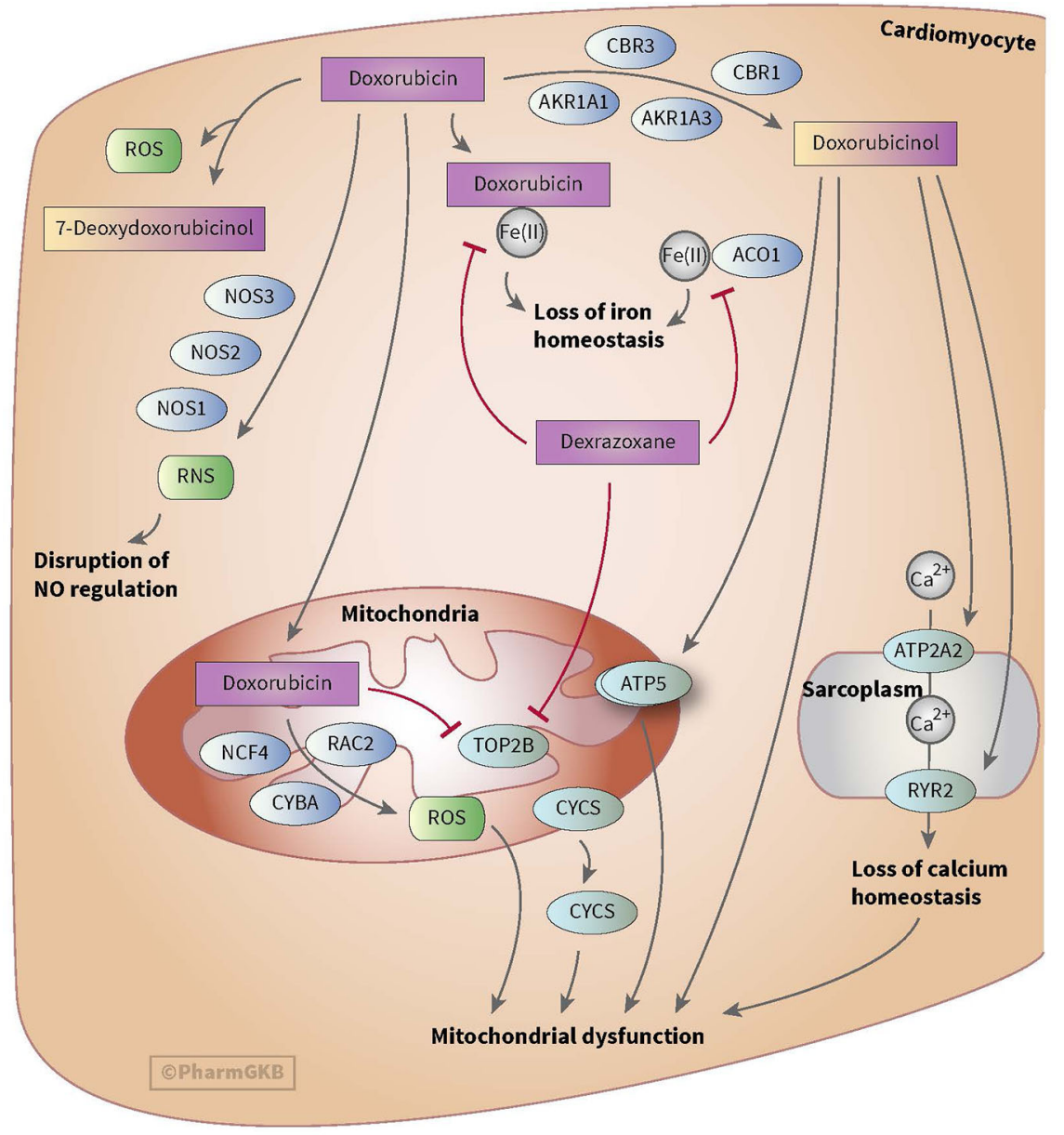

FIGURE 1 | Figure used with permission of PharmGKB (Thorn et al., 2011; Doxorubicin Pathway (Cardiomyocyte Cell) P, 2020). This is an example of genes involved in doxorubicin-induced cardiotoxicity. The presented genes (e.g. CBR, NOS, and AKR) are involved in the metabolizing and transport pathways of anthracyclines. The formation of ROS during the metabolism of anthracyclines is thought to play an important role in anthracycline-induced cardiotoxicity.

ABCC1 (rs3743527, rs246221) (Blanco et al., 2008), SLC28A3 (rs885004 and rs4877847), SLC22A17 (rs4982753, rs4149178) (Visscher et al., 2015), and sulfotransferase (SULT) SULT2B1 (rs12882406 and rs12896494) (Visscher et al., 2015) have been associated with cardiotoxicity during anthracycline treatment (Conyers et al., 2018). In recent years, three studies have focused on $A B C B 1, A B C C 1, A B C C 2, A B C C 5, A B C G 2, S L C 28 A 3$, and CYP3A5 (Krajinovic et al., 2016; Huang et al., 2017; Ruiz-Pinto et al., 2017).

A small Chinese study including 36 ALL patients showed no association between potential metabolizing $C Y P 3 A$ polymorphisms $\left(C Y P 3 A 5^{\star} 1-^{\star} 1, C Y P 3 A 5^{\star} 1{ }^{*} 3, C Y P 3 A 5^{\star} 3-{ }^{*} 3\right)$ and daunorubicin-induced cardiotoxicity (Huang et al., 2017). A study by Ruiz-Pinto et al. (2017) performed a GWAS with 93 pediatric cancer patients who had used doxorubicin, daunorubicin or epirubicin in the past. In this study, no association was found with transporter $A B C B 1$ and SLC28A3 polymorphisms and chronic anthracycline-induced cardiotoxicity. A retrospective cohort study by Krajinovic et al.
(Krajinovic et al., 2016) included 251 cALL patients and 44 cALL patients (validity set). Multiple polymorphisms in transporter genes $A B C C 1, A B C C 2, A B C C 5, A B C B 1$, and $A B C G 2$ were investigated for associations with doxorubicin-induced cardiotoxicity. The ABCC5 (rs7627754) was found to be significant associated with a lower ejection fraction (EF) and shortening fraction (SF) 3 years after diagnosis, suggesting a possible higher risk for cardiotoxicity with patients carrying this polymorphism.

\section{Genetic Variants Involved in ROS Prevention}

Genetic variants involved in ROS prevention have received much attention in past studies (Aminkeng et al., 2016; Bansal et al., 2017; Chang and Wang, 2018). These include genetic variations in NADPH oxidase, Ras-related C3 botulinum toxin substrate 2 (RAC2) (Aminkeng et al., 2015), neutrophil cytosolic factor 4 (NCF4) (Visscher et al., 2012), Cytochrome B-245 Alpha Chain (CYBA) (Visscher et al., 2012; Windsor et al., 2012; Armenian et al., 2013) and catalase (CAT) (Rajić et al., 2009; Aminkeng 


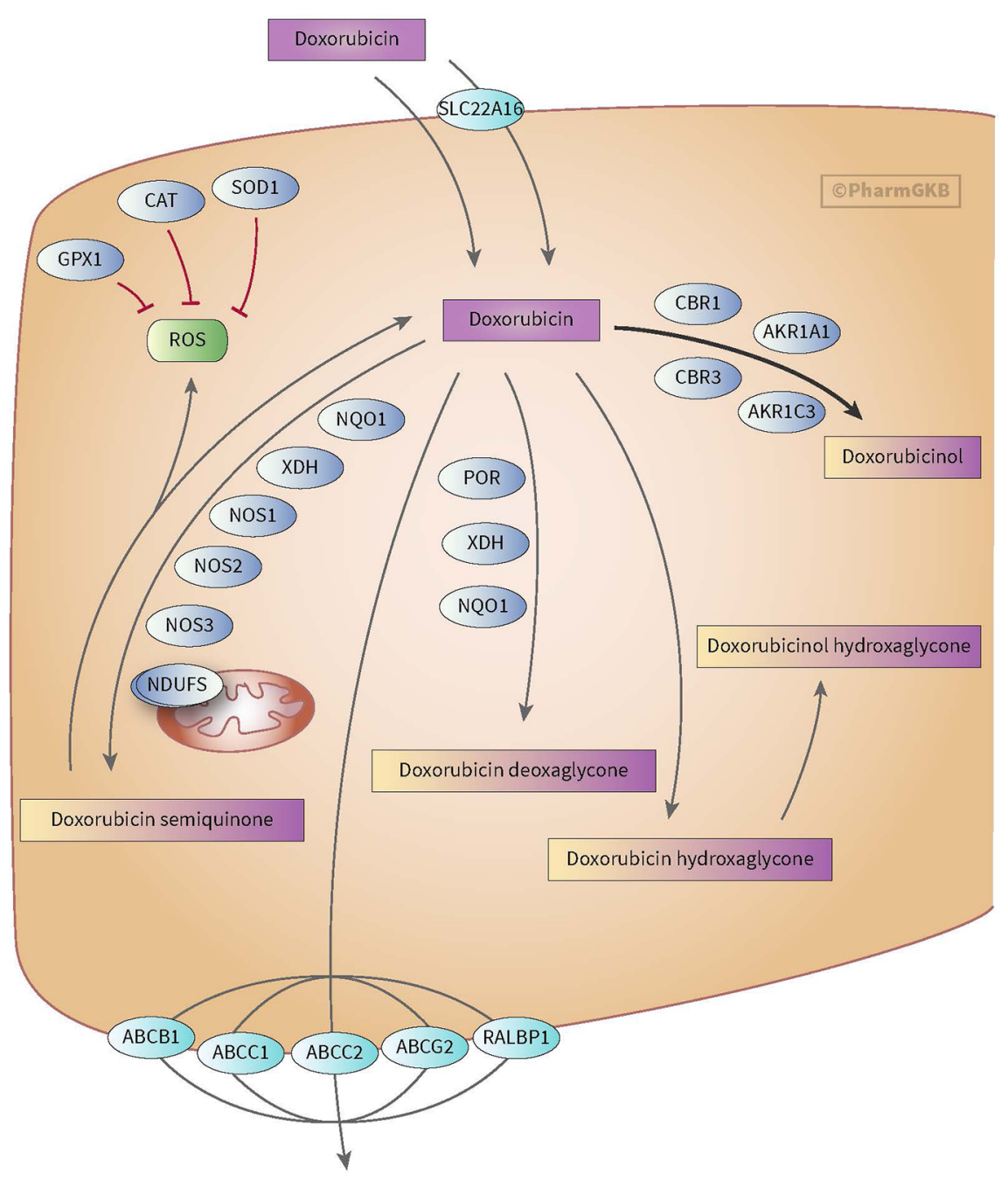

FIGURE 2 | Figure used with permission of PharmGKB (Thorn et al., 2011; Doxorubicin Pathway, 2020). This is an example of genes involved in doxorubicin pharmacokinetic pathway. These include metabolizing genes such as CBR, AKR, and NOS as well as SLC and ABC transporters.

et al., 2015; Aminkeng et al., 2016; Conyers et al., 2018). However, results in relation to these gene variants and anthracycline-induced cardiotoxicity remain inconsistent. One recent study investigated the role of polymorphisms involved in ROS prevention. A study by Krajinovic et al. (2016) found a possible protective effect of NOS3 (rs1799983) leading to lower risk of developing chronic doxorubicin-induced cardiotoxicity.

\section{Other Polymorphisms}

Four recent studies discussed polymorphisms in genes not clearly relatable to the known mechanisms of action of anthracyclines.

Wang et al. (2016) found an association between CUGBP Elav-Like Family Member 4 (CELF4) (rs1786814) and anthracycline-induced cardiotoxicity. CELF4 is involved in cardiac dysfunction and fibrosis. In this study, patients carrying CELF4 (rs1786814) had a higher risk of developing anthracyclineinduced cardiotoxicity. This risk increased significantly when patients received an anthracycline dose above $300 \mathrm{mg} / \mathrm{m}^{2}$. Hildebrandt et al. (2017) showed a significant protective effect of 1-Phosphatidylinositol-4,5-bisphosphate phosphodiesterase epsilon-1 (PLCE1) (rs932764) and ATPase Plasma Membrane Ca2+ Transporting 1 (ATP2B1) (rs17249754) in chronic anthracycline-induced cardiotoxicity. The anthracyclines used were not specified in this study. PLCE1 and ATP2B1 are involved in calcium signaling in cells. Krajinovic et al. (2016) showed no significant associations between polymorphisms in MutL homolog 1 (MLH1), MLH2 and GSTs and chronic doxorubicin-induced cardiotoxicity. $M L H 1$ and $M L H 2$ are genes playing a role in DNA repair and GSTs are detoxifying enzymes. Another recent study by Singh et al. (2020) investigated the role of GSTM1 in chronic anthracycline-induced cardiotoxicity. They found that patients carrying GSTM1 null genotype (i.e. enzyme activity is absent) had an increased risk of cardiomyopathie. This risk did not increase with patients who received anthracycline-doses of $\geq 250 \mathrm{mg} / \mathrm{m}^{2}$. Ruiz-Pinto et al. 
(2017) showed a significant association between chronic anthracycline (i.e. doxorubicin, daunorubicin or epirubicin)induced cardiotoxicity and $G$ protein-coupled receptor family 35 (GPR35) (rs12468485) gene. Patients carrying GRP35 (rs12468485) developed cardiotoxicity more frequently.

\section{Other Anthracycline-Induced Toxicities}

One recent study investigated the role of Glucose-6-fosfaatdehydrogenase $(G 6 P D)$ (gene involved in the pathway of detoxifying ROS) normal or deficient enzyme function with daunorubicin-induced hematotoxicity. A retrospective study of Robinson et al. (2019) showed no association between G6PD normal of deficient function and daunorubicininduced hematotoxicity.

Most recent studies focused on polymorphisms in metabolism and transport genes. More recently, other genetic variants are discovered through GWAS which play a possible role in toxicities of anthracyclines. However, there is no consensus on the role of metabolism, transport and other gene variants in anthracycline-induced toxicities, and more research is needed to confirm associated findings and propose dose adjustments to minimalize anthracycline-induced (cardio)toxicity.

\section{Asparaginase}

Asparaginase is a chemotherapeutic agent derived from bacteria E. Coli (Oncaspar ${ }^{\circledR}$ ) and Erwinia chrysanthemi (Erwinase ${ }^{\circledR}$ ) and is used in the treatment for acute lymphatic leukemia (Verma et al., 2007). Asparaginase catalyzes the deamination of asparagine to aspartic acid and ammonia, leading to a reduced serum asparagine concentration and leukemic cell death (Hijiya and van der Sluis, 2016). Unfortunately, asparaginase causes severe toxicities such as hypersensitivity, hepatotoxicity, pancreatitis, and thrombosis. These toxicities lead to therapy resistance, treatment discontinuation and eventually poor clinical outcomes (Hijiya and van der Sluis, 2016; Rank et al., 2019). A study by Rank et al. (2019) showed that pancreatitis occurred in up to $11 \%$ of children treated with asparaginase and $44 \%$ of patients re-exposed to asparaginase experienced a second episode of pancreatitis.

\section{Genetic Variances and Toxicity}

Over the last years, an increasing number of studies have reported associations between genetic variants and asparaginase toxicities (Abaji and Krajinovic, 2016; Lee and Yang, 2017; Lopez-Santillan et al., 2017; Rank et al., 2019). Genetic variants in asparagine synthase (ASNS), human leukocyte antigens (HLA) (Abaji and Krajinovic, 2016) and the glutamate Ionotropic Receptor AMPA Type Subunit 1 (GRIA1) have been found to influence asparaginase toxicity (Lee and Yang, 2017; Lopez-Santillan et al., 2017). Recently, eight studies investigated four asparaginase-induced toxicities (hypersensitivity, pancreatitis, thrombosis, and hepatotoxicity).

One GWAS by Abaji et al. (2017) assessed the association between asparaginase-induced hypersensitivity, pancreatitis, and thrombosis and polymorphisms. Three genetic variants, transporter SLC7A13 (rs9656982), Myb-binding protein 1A (MYBBP1A) (rs3809849) (involved in embryonic and cellular development such as mitosis) and YTH Domain Containing 2 (YTHDC2) (rs75714066) (involved in regulate mRNA translation and stability), were associated with a higher risk of developing hypersensitivity. Three polymorphisms, ADAM Metallopeptidase With Thrombospondin Type 1 Motif 17 (ADAMTS17) (rs72755233) (function unknown), MYBBP1A (rs3809849) (involved in many cellular processes such as syntheses of ribosomal DNA) and Sperm Antigen With Calponin Homology And Coiled-Coil Domains 1 (SPECC1) (rs9908032) (function unknown), were associated with a higher risk of pancreatitis. Six polymorphisms were associated with a higher risk of thrombosis. These were Polycystin 2 Like 1, Transient Receptor Potential Cation Channel (PKD2L1) (rs6584356) (involved in cell-cell/ matrix interactions), Ras And Rab Interactor 3 (RIN3) (rs3742717) (functions as a guanine nucleotide exchange for genes $R A B 5 B$ and $R A B 31$ ), Sperm Flagellar 2 (SPEF2) (rs34708521) (involved in axoneme development), Macrophage Expressed 1 (MPEG1) (rs7926933) (involved in cell cycle), interleukin-16 (IL16) (rs11556218) (involved in immune system), and SLC39A12 (rs62619938).

A GWAS by Højfeldt et al. (2019) found a significant higher risk of hypersensitivity with CCR4-NOT Transcription Complex Subunit 3 (CNOT3) (rs73062673). Among other functions, this gene is involved in the regulation of human leukocyte antigen (HLA) gene transcription. While no significance was reached on a genome-wide significance level, Højfeldt et al. also discovered two gene risk variants (i.e. HLA-DQA1 (rs9272131) and the antigen peptide transporter 2 (TAP2) which showed a higher frequency of asparaginase hypersensitivity with patients carrying these variants. These results show that variants in the HLA regions as well as genes regulating expression of these variants are involved in asparaginase hypersensitivity. To further investigate the role of HLA gene variants and asparaginase hypersensitivity, a study by Kutszegi et al. (2017) investigated HLADRB1, HLADQB1, and HLADQA1 alleles (both HLA class II alleles). They showed a significant higher risk of developing hypersensitivity for $H L A-D R B 1^{\star} 07: 01, H L A-D B Q 1^{\star} 02: 02$, and $H L A-D Q A 1^{\star} 02: 01$ carriers. Also, 27 amino acid positions in HLA class II alleles were found to be significant association with a higher risk for hypersensitivity as well as two haplotypes. These findings are replicated and also confirmed by Gagné et al. (2020).

Three GWAS studies analyzing multiple polymorphisms showed significant associations with asparaginase-induced pancreatitis (Liu et al., 2016; Liu et al., 2017; Wolthers et al., 2017). A GWAS by Liu et al. (2016) generated sixteen carboxypeptidase A2 (CPA2) single-nucleotide polymorphisms (SNP) that were associated with pancreatitis (highest association with rs199695765). However, this could not be reproduced by Wolthers et al. (2017). Wolthers et al. (2017) found associations with fourteen SNPs in the theunc-51-like kinase 2 (ULK2) gene (highest association with rs281366) and one SNP in G-protein signaling 6 ( $R G S 6)$ gene (rs17179470), nuclear factor of activated T cells 2 (NFATC2, rs62228256), pancreatic secretory trypsin 
inhibitor (SPINK1, rs17107315), chymotrypsin C (CTRC, rs10436957), and Claudin-2 (CLDN2, rs4409525) (Wolthers et al., 2019). The proteases cationic and anionic (PRSS1-PRSS2, rs13228878, and rs10273639) reduced the risk of pancreatitis (Wolthers et al., 2019).

One GWAS by Liu et al. (2017) investigated the role of polymorphisms in hepatotoxicity during asparaginase treatment. They found that higher alanine aminotransferase (ALT) levels were associated with patatin-like phospholipase domain-containing protein 3 (PNPLA3) (rs738409) (involved in the balance of energy usage and storage in adipocytes).

Studies included in this review added new knowledge to genes and polymorphisms that could play a role in asparaginase toxicity. Previous studies found associations between polymorphisms in asparagine synthase (ASNS gene), human leukocyte antigens (HLA gene) (Abaji and Krajinovic, 2016) and the glutamate receptor (GRIA1 gene) and asparaginase toxicity (Lee and Yang, 2017; Lopez-Santillan et al., 2017; Hojfeldt et al., 2019).

\section{Methotrexate}

Methotrexate (MTX) is widely used in pediatric oncology treatment protocols of both hematological malignancies (including ALL) as well as solid tumors. MTX is administrated through various ways of administrations and dosages. These include high intravenous (IV) dosage $\left(>500 \mathrm{mg} / \mathrm{m}^{2}\right.$, up to $12 \mathrm{~g} /$ $\mathrm{m}^{2}$ ), low oral dosages during the maintenance phase as well as intrathecal administration. The drug has shown great benefit in many cancer treatments, but is also associated with various toxicities, ranging from gastro-intestinal toxicity (including severe mucositis), hepatic toxicity, neurotoxicity, nephrotoxicity, and hematological toxicity. These toxicities show large inter-individual differences in pediatric patients. Not only toxicity has been found to be unpredictable, also variations in MTX activity and resistance or reduced sensitivity have been seen in clinical settings.

\section{Metabolism and Transport}

MTX acts by inhibiting the folate acid cycle, resulting in impairing nucleic acid syntheses. Its pharmacological action follows a complex pattern, with many metabolic enzymes, transporters, and targets. Genetic variants may influence the pharmacological action of MTX in several ways, and many candidate polymorphisms have been studied in relation to folate pathways or MTX metabolism, in search for correlation with response or toxicity of MTX.

\section{Genetic Variances and Toxicity}

MTX enters the cell through active transport through reduced folate carrier (SLCO1B1/RFC1). Efflux transporter gene belongs to the $A B C$ superfamily, including $A B C$ transporters such as $A B C B 1$. The OATP transporter family is expressed in a variety of tissues and organs important for, among others, MTX elimination. Across the blood-brain barrier, MTX undergoes saturable efflux, presumably through $A B C G 2$ and organic anion transporter OAT3 (see Figure 3) (Mikkelsen et al., 2011; Franca et al., 2017; Methotrexate Pathway, 2020). MTX is intracellularly metabolized to its active polyglutamate form (MTX-PGs) by folylpolyglutamate-synthetase (FPGS) and gamma-glutamyl hydrolase $(G G H)$ enzymes. GGH enzymes catalyzes the removal of polyglutamates

Polymorphism in genes, coding for these transporters, have been studied for associations with an altered clearance and sensitivity of MTX (e.g. $A B C B 1$ and $A B C C 4$ genes), but results have been inconsistent (Ramírez-Pacheco et al., 2016; Hegyi et al., 2017). Genetic polymorphism in the ABC-transporter genes are believed to result in failure of the excretory system, prolonged MTX exposure and have been associated with higher incidence of myelosuppression during MTX treatment (Mlakar et al., 2016).

Recently, SLCO1B1 gene (encoding for OATP1B1 transporter) has gained interest. The OATP1B1 transporter, located on the membrane of human hepatocytes, mediates disposition of many medications. SLCO1B1 polymorphisms have been associated with lower MTX clearance, nephrotoxicity, and GI toxicity (Liu et al., 2017). While the association for SLCO1B1 could not be replicated by Razali et al. (2020), they did show a possible increased risk of leukopenia with ABCC2 (rs717620) or the transcriptional factor of B lymphocyte progenitors ( $A R I D 5 B$, rs4948496) carriers. Patients with genetic variants in SLCO1B1 may benefit from increased precautionary measures like more aggressive hydration and alkalization (Mlakar et al., 2016).

SLCO1A2 (encoding for OATP1A2 transporter) plays a role in MTX elimination. A microRNA (miR) binding site polymorphism in SLCO1A2 (rs4149009) showed delayed MTX excretion in Chinese population (Wang et al., 2018).

Preliminary evidence showed that SLC19A1 polymorphism (SLC19A1 80G>A), an influx transporter involved in MTX uptake in gut and liver cells, may have a protective effect on the occurrence of mucositis (Park and Shin, 2016; Kotnik et al., 2017). GGH polymorphism (GGH_16T/C) has been described in relation to MTX associated hepatotoxicity in osteosarcoma patients (Hattinger et al., 2016).

Based on recent studies, genetic variance in transporter or metabolizing enzymes is expected to have influence on the exposure of MTX and its toxicity. However, given the complex route of metabolism and transport of MTX, a simple PGx model will probably not suffice.

\section{Genetic Variances and Target}

Both MTX and MTX-PGs inhibit dihydrofolate reductase (DHFR), an enzyme that catalyzes the conversion of dihydrofolate to its active form tetrahydrofolate. Tetrahydrofolate deficiency leads to the depletion of intracellular folates, resulting in decreased synthesis of nucleic acids and cell death. MTX-PGs also interfere with methylenetetrahydrofolate reductase (MTHFR), an enzyme which plays a major part in intracellular folate metabolism. Another enzyme target of MTX is thymidylate synthetase (TYMS), responsible for synthesis of a precursor of DNA synthesis.

Variants in MTHFR activity have been described and the role of MTHFR polymorphism (mainly C677T and A1298C genotypes) in relation to toxicity has been studied by several groups (Campbell et al., 2016; Ramírez-Pacheco et al., 2016; 


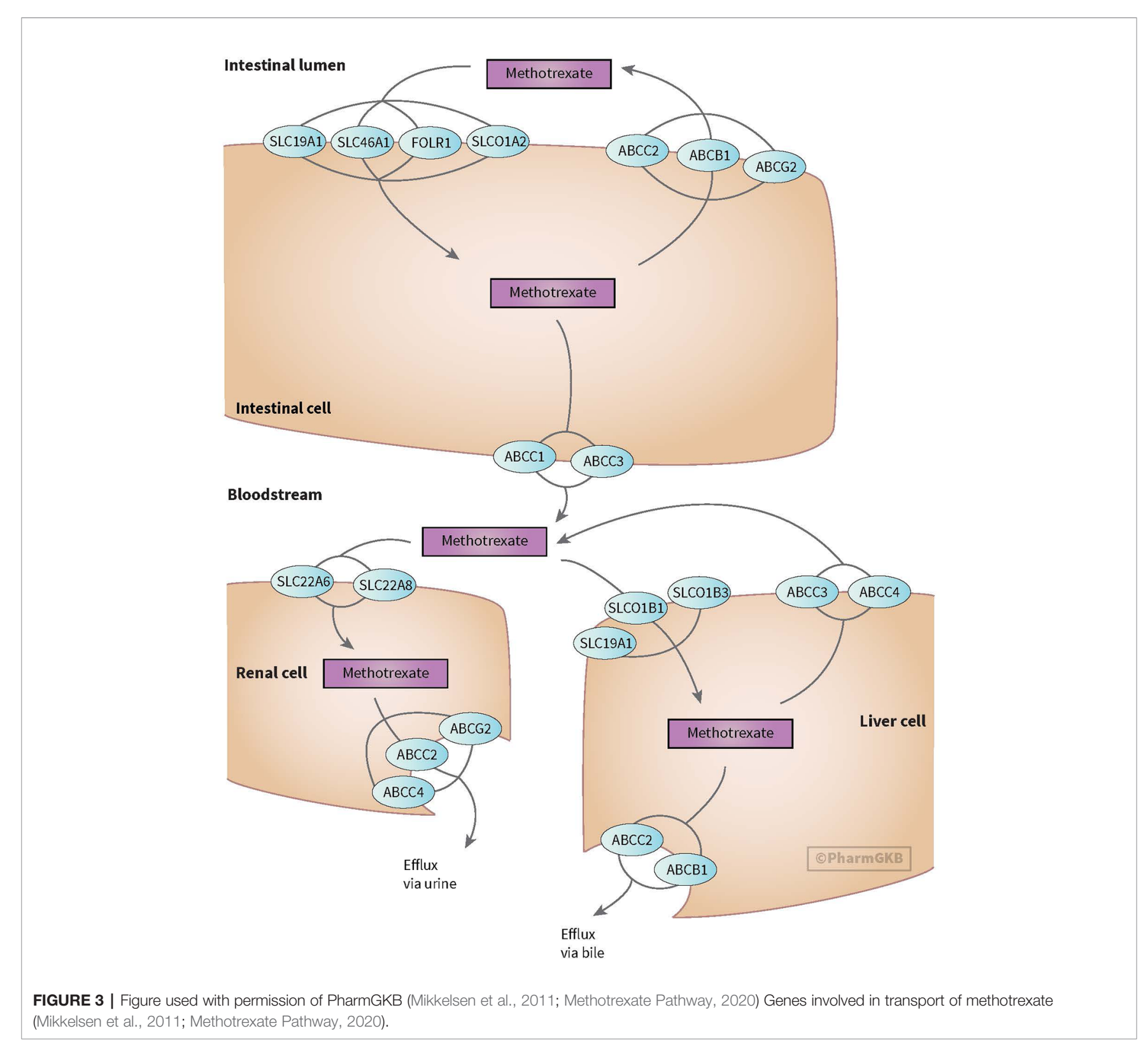

Mahmoud et al., 2018; Zhu et al., 2018; Yousef et al., 2019). However, recent reviews summarized the available data and showed ambiguous results (Umerez et al., 2017; Yao et al., 2019), concluding no clear correlation could be established between MTHFR polymorphism and MTX toxicity or relapse data.

DHFR and TYMS genes have also been studied in smaller cohorts in relation to hematological toxicity of MTX and to intrinsic resistance to MTX (Yousef et al., 2019). However, these results have also been inconclusive.

\section{Neurotoxicity, Hepatotoxicity, and Mucositis}

MTX and MTX-polyglutamates (MTX-PGs) interfere with the adenosine pathway by inhibiting 5-aminoimidazole-4- carboxamide ribonucleotide formiltransferase (ATIC) and promoting adenosine release. This pathway has been implicated in MTX-associated neurotoxicity. Adenosine receptor ADORA2A polymorphisms have been associated with MTX related leukoencephalopathy in a small cohort study (Tsujimoto et al., 2016) and with an increased risk on hepatotoxicity (Franca et al., 2017). A study performed by Gutierrez-Camino et al. (2017b) replicated results showing an association between MTX-induced mucositis and miR-1206 variant (rs2114358) in ALL patients.

In summary, many efforts have been undertaken to associate polymorphism in enzymes involved in metabolic routes or targets of MTX with toxicity or activity. These were mainly based upon pediatric cohorts of patients with ALL or osteosarcoma. Despite several positive associations, replication in other cohorts has been 
difficult and evidence for the association between polymorphism and MTX toxicity is still inconsistent. Currently, pharmacokinetic $(\mathrm{PK}) /$ pharmacodynamic (PD) monitoring of MTX treatment is still mandatory as the genomic complexity associated with MTX treatment hampers the preemptive use of $\mathrm{PGx}$ to predict variability in toxicity or response in individual patients.

\section{Platinum Compounds}

In pediatric oncology, platinum compounds such as cisplatin and carboplatin are widely used in solid malignancy and neuro oncology treatments. Similar to alkylating agents, they cause DNA damage by establishing crosslinks within and between DNA strands. Characteristic toxicities of platinum compounds include nephrotoxicity, neurotoxicity, and ototoxicity.

\section{Metabolism and Transport}

Platinum compound transport is handled by several enzymes, including copper uptake protein 1 (CTR1), ABCC2, coppertransporting P-type ATPase (ATP7A), and ATP7B. Inside the nucleus, platinum-DNA adducts are formed. Several mechanisms influence the impact of DNA damage caused by platinum compounds, including recognition of platinum-DNA adducts (HMGB1), DNA mismatch repair (MSH2, MSH6, MLH1, and PMS1 Homolog 2, Mismatch Repair System Component (PMS2), nucleotide excision repair (X-Ray Repair Cross Complementing 1 (XRCC1), ERCC excision repair 1, endonuclease non-catalytic subunit (ERCC1), ERCC2, ERCC3, ERCC4, ERCC6, DNA Damage Recognition and Repair Factor (XPA) and SWItch/ Sucrose Non-Fermentable (SWI/SNF) and translesion synthesis (DNA Polymerase Eta $(P O L H)$ and DNA polymerase Beta $(P O B L)$. Furthermore, several genes (Myeloperoxidase $(M P O)$, superoxide dismutase (SOD1), GSTM1, NQO1, GSTP1, GSTT1, $M T 1 A$, and MT2A) may lower the intracellular concentration of platinum compounds (Platinum Pathway Pharmacokinetics/ Pharmacodynamics, 2020).

\section{Genetic Variances and Toxicity Nephrotoxicity}

Platinum compounds, mainly cisplatin, cause damage to the proximal tubules in the kidney, leading to acute kidney injury and electrolyte disturbances. Variants in ERCC1 (rs3212986) (Khrunin et al., 2010; Tzvetkov et al., 2011), EPHX1 (rs1051740) (Khrunin et al., 2014), organic cation transporter-2 (OCT2) (rs596881) and CTR1 (rs12686377 and rs7851395) (Chang et al., 2017) have been associated with a reduced risk of renal toxicity in adult patients. All these genes play a role in platinum compound uptake and handling. No recent PGx studies were found regarding platinum compound nephrotoxicity in pediatric oncology populations.

\section{Neurotoxicity}

Platinum-induced peripheral neuropathy may lead to (irreversible) sensory and motor dysfunction. It is a dosedependent phenomenon, which could be progressive months after treatment, leading to significant long-term disability. In a cohort of adult testicular cancer survivors, a GWAS revealed a correlation between reduced expression of Regulation Of
Nuclear Pre-MRNA Domain Containing 1B (RPRD1B) and cisplatin-induced peripheral neuropathy (Dolan et al., 2017). $R P R D 1 B$ is thought to play an important role in several DNA repair mechanisms. There are no data available on PGx of platinum-induced neuropathy in children.

\section{Ototoxicity}

Among platinum compounds, cisplatin imposes the highest risk of irreversible sensorineural hearing loss. Known concomitant risk factors include higher cumulative dose, younger age, treatment with additional ototoxic drugs and cranial irradiation. Several genetic variants related to cisplatin ototoxicity, includes rs12201199 in TPMT, rs9332377 in catechol-O-methyltransferase (COMT) (Ross et al., 2009), and rs62283056 in Wolframin ER Transmembrane Glycoprotein (WFS1) (Wheeler et al., 2017). However, results concerning these genes are conflicting (Thiesen et al., 2017).

A genetic variant (rs1872328) in Acylphosphatase 2 (ACYP2), coding for a protein thought to be responsible for hair cell development, was found to be significantly associated with hearing loss in pediatric patients treated with cisplatin for embryonal tumors (Xu et al., 2015) and osteosarcomas (Vos et al., 2016). Recently, a variant in GSTP1 (rs1695), coding for a detoxification enzyme, was found to be associated with an elevated risk of hearing loss in pediatric patients treated with cisplatin or carboplatin (Liberman et al., 2018). Another recent study investigated the role of genes responsible for nucleotide excision repair in DNA (Turan et al., 2019). However, no significant association between ototoxicity and ERCC1 (rs25487), ERCC2 (rs13181), and XRCC1 (rs11615) was found.

Apart from genetic factors, epigenetic factors influencing cisplatin ototoxicity have recently come to attention. In a pediatric medulloblastoma and primitive neuroectodermal tumor patient cohort, Brown et al. (2017) found an association between increased cisplatin ototoxicity susceptibility and a methylation locus (cg14010619) in the P21 (RAC1) Activated Kinase 4 (PAK4 gene). This gene is responsible for stereociliary bundle migration in inner and outer cochlear hair cells.

In conclusion, PGx studies concerning platinum compound toxicity in pediatric populations have so far focused on ototoxicity. The results of these studies, however, have not yet resulted in PGx based dosing recommendations.

\section{Glucocorticosteroids}

Glucocorticosteroids (GCs) play a major role in the treatment of pediatric cancer. Despite significant benefits of high-dose GCs, treatment is associated with toxicities like hepatotoxicity, hypertension, muscle wasting, metabolic effects, neuropsychiatric effects, osteonecrosis, and osteoporosis.

\section{Metabolism and Transport}

Glucocorticoids (GC) exert their activity by reducing cell proliferation and promoting apoptosis or cell arrest by binding to intracytoplasmic glucocorticoid receptors (GR/NR3C1). Three polymorphisms in the $N R 3 C 1$ gene are known to be associated 
with reduced sensitivity of GCs: TthIIII (rs10052957), ER22/23K (rs6189/rs6190), and GR-9 $\beta$ (rs6198). In contrast, N363S (rs6195) and BC1I (rs41423247) are associated with an increased sensitivity to GC (van Rossum and Lamberts, 2004).

GCs are metabolized in the liver primarily via CYP3A4. Expression of CYP3A4 varies between individuals and has been associated with outcome in adult cancers (Miyoshi et al., 2002). Differences in expression of CYP3A4 may be explained by polymorphisms in nuclear receptors $(N R 112)$ that are involved in the transcriptional regulation of CYP3A4 (Lamba et al., 2010).

GCs are mainly transported by a multidrug resistance protein encoded by $A B C B 1$. Inter-individual variability in the expression of multidrug resistant gene (MDR1) is observed and may influence the efficacy of GCs. Furthermore, GSTs are involved in several cellular processes and genes of the BCL2 family are involved in the apoptotic response of GCs.

\section{Genetic Variances and Toxicity}

Numerous studies have investigated the potential link between polymorphisms in the NR3C1, CYP3A4, ABCB1, GST, and BCL2 genes and GC response and toxicity, but have yielded conflicting results and so far, none of the studied genetic variants has been implemented in the treatment of cancer. In the past four years only a few new studies have been published.

A recent study including 346 pediatric ALL patients showed that patients with $\mathrm{N} 363 \mathrm{~S}$ genotype in the $N R 3 C 1$ gene were more prone to steroid-induced toxicities during ALL treatment. Hepatotoxicity was significantly more frequent among patients with N363S genotype than non-carriers (Eipel et al., 2016). This underlines the hypothesis that increased GC sensitivity due to a polymorphism might lead to increased susceptibility to steroidinduced toxicity. A study by ElFayoumi et al. (2018) associated a polymorphism in the ABCB1 (rs1045642 C3435T) gene with lifethreatening infections due to GC treatment.

Bone fractures and osteonecrosis have most frequently been attributed to exposure to GCs. Two polymorphisms in the BCL2L11 gene (891T>G rs2241843 and 29201C>T rs724710), encoding Bim protein, were significantly associated with steroidinduced osteonecrosis in children with ALL. The 891T $>$ G was also confirmed in a replication cohort and influenced in vitro Bim gamma isoform levels. Bim proteins are believed to be involved in the sensitivity of ALL cells to corticosteroid-induced apoptosis (Plesa et al., 2019). A GWAS in children with ALL and osteonecrosis showed that the SNP rs10989692 near the glutamate receptor GRIN3A locus, was associated with osteonecrosis (Karol et al., 2015). Glutamate receptor variants were previously associated with arterial embolism and thrombosis (Lin et al., 2013). GCs have been shown to induce the expression of glutamine synthetase in osteoblasts (Olkku et al., 2004). Hence, variations in the glutamate receptors may contribute to vascular events leading to osteonecrosis in patients exposed to GC therapy (Karol et al., 2015). Meanwhile bone toxicity has mainly been considered a consequence of exposure to corticosteroids during ALL therapy (Mattano et al., 2000; Girard et al., 2013). Recently, the TS variant $2 \mathrm{R} / 2 \mathrm{R}$ was associated with increased rise of osteonecrosis among children younger than 10 years at diagnosis suggesting that MTX may play a pathophysiologic role in the development of osteonecrosis (Finkelstein et al., 2017). Although evidence is limited, published data describe a positive association between polymorphisms in GC pathways and the efficacy and toxicity of GCs. Its impact on outcome is debatable since resistance to GC might be overcome by the effect of combination drug therapy. Concerning GC-induced toxicity larger studies are needed to investigate the role of genetic polymorphisms in the development of GC-induced toxicity to avoid severe complications.

\section{Thiopurines}

6-Mercaptopurine (6MP) is the cornerstone of the maintenance phase of ALL treatment in children and is used more often than its analogue tioguanine (TG). $6 \mathrm{MP}$ is required continuously for 2 to 3 years in leukemia treatment and used in oral dosages varying between 25 and $75 \mathrm{mg} / \mathrm{m}^{2}$. Known for its narrow therapeutic window, $6 \mathrm{MP}$ is able to cause severe toxicities including myelosuppression, hepatotoxicity, and GI toxicity. 6MP treatment interruption is known to increase the risk of relapse. It is therefore of great importance to find and maintain the optimal 6MP dosage in ALL patients.

\section{Metabolism and Transport}

$6 \mathrm{MP}$ is converted intracellularly by hypoxanthine guanine phosphoribosyl transferase (HPRT) into active 6-thioguanine nucleotides (6TG) which are incorporated into DNA, causing cell death. $6 \mathrm{MP}$ is methylated by the enzyme thiopurine Smethyltransferase (TPMT) into 6-methylmercapturine (6MMP). Methylated 6MP metabolites also contribute to the cytotoxic effects of $6 \mathrm{MP}$ by inhibiting de novo synthesis of purines. Increased levels of 6-TGN and 6-MMP have been associated with an increased risk of toxicity (Koutsilieri et al., 2019).

TPMP activity is well studied and shown to be highly variable among individuals, although the incidence of genetic variants differs between ethnic populations (Jimenez-Morales et al., 2016). In Caucasians, $90 \%$ to $95 \%$ of subjects have a normal/ high TPMT activity, 5\% to $10 \%$ reduced and around $0.5 \%$ an absent enzymatic activity (Franca et al., 2019). In Asian and Hispanic population, the incidence of variant TPMT genes is much lower (Koutsilieri et al., 2019).

Three variant alleles $T P M T^{\star} 2$ (G238C), TPMT ${ }^{\star} 3 A$ (G460A and $A 719 \mathrm{G})$ and $T P M T^{*} 3 \mathrm{C}(\mathrm{A} 719 \mathrm{G})$, account for more than $95 \%$ of the inherited variability in TPMT enzyme activity (Conyers et al., 2018), although more TPMT deficient variants have recently been identified, with a less frequent occurrence (Koutsilieri et al., 2019).

\section{Genetic Variances and Toxicity}

Polymorphisms in TPMT are well studied in relation to the risk of toxicity (mostly severe myelosuppression) and corresponding dosage adjustments (Jimenez-Morales et al., 2016). This has lead to implementation of Federal Drugs Authority (FDA) and European Medical Agency (EMA) supporting clinical 
guidelines for preemptive testing of TPMT, corresponding with lower starting dosages of $6 \mathrm{MP}$ for poor and intermediate metabolizers (Relling et al., 2020). In this review, one study examining the tolerable dose and treatment outcome within patients carrying TPMT and nudix hydrolase 15 (NUDT15) genetic variants is included, while dose adjustments for TPMT and NUDT15 intermediate and/or poor metabolizers are already used in practice (Liang et al., 2016).

The discovery of frequent thiopurine-induced myelosuppression in Asian populations, while TPMT variants rarely occur in these ethnic populations, has led to several studies on the role of NUDT15 and ITPA gene variants (Liang et al., 2016; Milosevic et al., 2018). NUDT15 dephosphorylates thiopurine active metabolites and reduces the formation of active 6TG nucleotides, whereas ITPA is assumed to stimulate the formation of 6TG nucleotides. Results with respect to the influence of ITPA polymorphism in relation to myelosuppression, hepatotoxicity or TGN formation have not been consistent and its clinical relevance is still controversial (Gerbek et al., 2018; Milosevic et al., 2018; Soler et al., 2018; Zhou et al., 2018; Khera et al., 2019; Wahlund et al., 2020). In contrast, in many recent studies, NUDT15 gene defects (rs116855232, rs186364861, rs869320766, rs201094029) have shown to result in increased TG availability for incorporation into DNA and have consistently been associated with TG toxicity including early myelosuppression (Chiengthong et al., 2016; Moriyama et al., 2016; Lee and Yang, 2017; Moriyama et al., 2017; Moriyama et al., 2017; Soler et al., 2018; Choi et al., 2019; Khera et al., 2019; Koutsilieri et al., 2019). The incidence of NUDT15 gene defects is higher in Asian and Hispanic populations, but NUDT15 genetic polymorphism has also been described in European patients (Schaeffeler et al., 2019). Therefore, the most recent CPIC guideline on thiopurines recommends both TPMT and NUDT genotyping (Koutsilieri et al., 2019; Relling et al., 2019).

Other SNPs that have been studied in relation to thiopurine sensitivity are variants within the phosphoribosylglycinamide formyltransferase (GART) gene (involved in folate cycle), Molybdenum Cofactor Sulfurase (MOCOS) gene (involved in thiopurine metabolism) and Protein Kinase C And Casein Kinase Substrate In Neurons 2 (PACSIN2) gene (involved in thiopurine metabolism (Smid et al., 2016; Franca et al., 2019). Polymorphisms in PACSIN2 have been associated with an increased risk of GI and hematologic toxicity during $6 \mathrm{MP}$ treatment. However, results have not been as convincing as TPMT and NUDT15 polymorphism (Choi et al., 2019). Genetic variants in Apurinic/Apyrimidinic Endodeoxyribonuclease 1 (APEX1) have been studied in relation to a more general sensitivity to antimetabolite active drugs, as human APEX1 is involved in DNA base excision repair pathway. In Asian populations APEX1 (rs2307486) variant resulted in an increased risk of 6MP-related early onset neutropenia (Kim et al., 2018).

Transporter genes have also been studied and variants in the $A B C B 1$ gene (C1236T) have found to be associated with increased sensitivity to 6MP (Gervasini et al., 2017), as well as variant genes in efflux transporter ABCC4 (Kim et al., 2018; Tanaka et al., 2018). These findings have been reported in small studies and need confirmation before being introduced in clinical practice.
In conclusion, in recent years evidence for preemptive TPMT and NUDT15 genotyping in facilitating tailored thiopurine treatment has been firmly established.

\section{Topoisomerase Inhibitors Topoisomerase I Inhibitors}

Topoisomerase I (Top 1) inhibitors act by preventing ligation of single strand breaks in DNA. In pediatric oncology, topoisomerase I inhibitors (such as irinotecan and topotecan) are used in the treatment of multiple solid malignancies. Topoisomerase I inhibitors are known to cause serious toxicities, such as myelosuppression and severe diarrhea. As not much is known on pharmacogenetic mechanisms involved in topotecan metabolism, this section will focus on irinotecan.

\section{Metabolism and Transport of Top 1 Inhibitors}

Irinotecan is a prodrug that is transported over hepatocyte cell membranes by several transporters (SLCO1B1, ABCB1, ABCC1, $A B C C 2$, and $A B C G 2)$. In the cytosol, it is converted to active compound SN-38 via carboxylesterase (CES1) and CES2. SN-38 actively inhibits topoisomerase I, forcing cells to arrest in $\mathrm{S}$ phase and leading to cell death. UGT1A1 detoxifies SN-38 through glucuronidation. UGT1A1 converts SN-38 into soluble and nontoxic $\mathrm{SN}-38$ glucuronic acid, which is released into the intestines. As diarrhea is caused by accumulation of SN-38 in intestinal mucosa, detoxification to SN-38 glucuronic acid is important for limiting this toxicity. Furthermore, irinotecan itself can be converted to inactive metabolites APC and NPC by CYP3A4 and CYP3A5. NPC can be converted to SN-38 by CES1 and CES2 (Mlakar et al., 2016).

\section{Genetic Variances and Toxicity in Top 1 Inhibitors}

Two genetic variants in UGT1A1 are known to significantly influence irinotecan metabolism. UGT1A1 ${ }^{\star} 28$ allele (rs8175347) is more prevalent in Caucasian and African American populations compared to East Asian populations (Zhang et al., 2007). It is a thymidine-adenosine (TA) repeat in the UGT1A1 promoter region, impairing transcription and therefore UGT1A1 enzyme function and SN-38 detoxification. This variant is associated with severe neutropenia and late diarrhea. According to the FDA drug label for irinotecan, dose reduction is recommended in adult $U G T 1 A 1^{\star} 28$ poor metabolizers. However, evidence in a pediatric population showed no severe toxicity when a low dose of irinotecan was used (Stewart et al., 2007). UGT1A1*6 allele (rs4148323) mainly occurs in East Asian populations. It is characterized by G71 to $\mathrm{R}$ substitution and causes decreased UGT1A1 enzyme function similar to the UGT1A1*28 allele (Etienne-Grimaldi et al., 2015).

Efforts to identify genetic variants that influence irinotecan toxicity are ongoing. Trubicka et al. (2017) found that pediatric medulloblastoma patients with variants in DNA repair genes (such as MSH2, RAD50, nibrin $(N B N)$, Fanconi anemia complementation group (FANCM), and exonuclease 1 (EXO1)) experienced significantly more adverse effects from treatment containing irinotecan. However, as these patients were treated with multiple drugs concomitantly, functional studies will be needed to elucidate the underlying mechanisms. 


\section{Topoisomerase II Inhibitors}

Topoisomerase II (Top 2) inhibitors, such as etoposide, prevent ligation of double strand breaks in DNA. Etoposide is widely used in the treatment of both solid and hematological malignancies in pediatric oncology. Toxicities include myelotoxicity and increased long-term risk of secondary malignancies (such as myeloid leukemia).

Although many enzymes are known to play a role in metabolism and transport of Top 2 inhibitors (among which are CYP3A4, CYP 3A5, and UGT1A), no variants of significant clinical impact have been identified to date (Khera et al., 2019).

\section{Vinca Alkaloids}

Vinca alkaloids are included in chemotherapy regimens of hematologic malignancies, solid tumors, and neuro-oncology. Their main mechanism lies in the disruption of microtubule function during cell division, leading to a metaphase arrest in the cell cycle and apoptosis (Moudi et al., 2013; van de Velde et al., 2017; Vinka Alkaloid Pathway, 2020). Peripheral neurotoxicity is a well-known side effect of vinca alkaloids, while primarily of vincristine (VCR). VCR-induced peripheral neuropathy has an incidence rate between $78 \%$ and $100 \%$ (Kandula et al., 2016) leading to muscle weakness and pain in hand and feet (van de Velde et al., 2017). It is dose-dependent and develops most severe at doses above $2 \mathrm{mg} / \mathrm{m}^{2}$ (Park et al., 2013). Therefore, in pediatric oncology a dose maximum of vincristine is fixed at $2 \mathrm{mg}$ to prevent severe neurotoxicity (Kandula et al., 2016).

Genetic polymorphisms are believed to play a role in a patients' sensitivity for VCR-induced neurotoxicity. These include genes involved in metabolism and transport out of (hepatic) cells of vinca alkaloids as well as genes involved in pharmacodynamics, stabilization, and formation of microtubules and nerves and inherited neuropathy genes (van de Velde et al., 2017). In this review we were only able to update vincristine (VCR) PGx in ALL patients as our literature search revealed no recent studies regarding vinblastine or vinorelbine or other pediatric cancer populations.

\section{Metabolism}

CYP3A4 and CYP3A5 enzymes are involved in the metabolism of vinca alkaloids in the liver and particularly known for VCR metabolism (Vinka Alkaloid Pathway, 2020). Four recent studies showed no association between vincristine (neuro)toxicity and polymorphisms in metabolizing enzymes.

In a retrospective study by Franca et al. (2017) 28 single nucleotide polymorphisms (SNPs) and two deletions genes involved in efficacy and adverse effects were collected to find an association between the polymorphisms and grade III/IV gastrointestinal, hepatic, and neural toxicity. Before adjusting for multiple variables, four genes were found to be associated with vincristine related toxicities. ITPA (rs1127354) increased the risk of neurotoxicity and gastrointestinal toxicity, while ADORA2A (rs2236624) was found the associated with hepatic toxicity. After adjustment for multiple variables, none of the associations remained significant (Franca et al., 2017). McClain et al. (2016) performed a retrospective study with 239 Hispanic ALL patients, analyzing $C Y P 3 A 5$ extensive $\left({ }^{*} 1 /{ }^{*} 1\right), C Y P 3 A 5$ intermediate $\left({ }^{*} 1 /\right.$ $\left.{ }^{\star} 3,{ }^{\star} 1 /{ }^{\star} 6,{ }^{\star} 1 /{ }^{\star} 7\right)$ and $C Y P 3 A 5$ poor metabolizers $\left({ }^{\star} 3 /{ }^{*} 3,{ }^{\star} 3 /{ }^{\star} 6,{ }^{\star} 3 /\right.$ ${ }^{\star} 7$ ). No significant association was found between CYP3A5 polymorphisms and vincristine-induced peripheral neuropathy (VIPN). Skiles et al. (2018), included a cohort of 78 Kenyan children to find an association between CYP3A5 and VIPN. Ninety one percent of the children were CYP3A5 high-expresser genotypes and none developed neuropathy, leading to no conclusive results.

Results in the past are conflicting, showing associations as well as no associations between $C Y P 3 A 4, C Y P 3 A 4^{\star} 1 B, C Y P 3 A 5$, CYP3A5*3, and VIPN (Kandula et al., 2016; Mora et al., 2016; van de Velde et al., 2017; Conyers et al., 2018).

\section{Transport}

Vinca alkaloids are transported out of cells through $A B C B 1$, $A B C C 1, A B C C 2, A B C C 3, A B C C 10$, and RalA-binding protein 1 ( $R A L B P 1)$. Seven recent studies investigated polymorphisms in transport genes and the risk on developing vincristine neurotoxicity. One study showed a significant association between $A B C C 1$ (rs3784867) and VIPN.

As stated above, Franca et al. (2017) investigated 28 SNPs and two deletions, including $A B C C 1$ (rs35592, rs246240, rs3784864, rs11075291) and $A B C C 2$ (rs17222723). Before adjustment for multiple variables, $A B C C 1$ (rs246240) was associated with increased the risk of neurotoxicity. After adjustment, this result did not reach significance. Lopez-Lopez et al. (2016) performed a retrospective study including 152 B-cell ALL Spanish patients. In this study 150 genetic variants involved in VCR pharmacokinetics and 13 microRNAs were analyzed. A significant higher risk of developing neurotoxicity grades 1 to 4 during vincristine treatment was found for rs3740066 and rs12826 in the $A B C C 2$ gene. Zgheib et al. (2018) assessed the association between grade II or higher VIPN and $A B C B 1$ (rs1045642), $A B C B 1$ (rs1128503) and $A B C C 2$ (rs717620). The study included 133 Arab ALL patients, where 19.5\% developed VIPN. None of the polymorphisms showed a significant association with VIPN. In a retrospective study by Wright et al. (2019), a higher risk of VIPN was associated with ABCC1 (rs3784867).

Gutierrez-Camino et al. (2017a) performed a retrospective study including 179 Spanish children with B-cell ALL. In this study, the authors analyzed 154 microRNAs (miRNAs) to find an association between the miRNAs and vincristine neurotoxicity. Three miRNAs were found most significant before corrections. These were miR-3117 (rs12402181) involved in ABCC1 and RalAbinding protein 1 (RALPBP1) expression, miR-4481 (rs7896283), and miR-6067 (rs35650931). miR-3317 and miR-6067 were associated with a decrease risk of neurotoxicity during vincristine treatment, while miR-4481 was associated with a higher risk of neurotoxicity. After multivariable correction, none of the miRNAs produced a significant result.

\section{Pharmacodynamics, Stability of Microtubules and Neurotoxicity Sensitivity}

Polymorphisms in pharmacodynamics (i.e. actin gamma 1 (ACTG1) (Ceppi et al., 2014), formation and stabilization of microtubules (i.e. Centrosomal Protein 72) (CEP72) (Diouf et al., 
2015), Microtubule Associated Protein 4 (MAP4) (Ceppi et al., 2014), Capping Actin Protein, Gelsolin Like (CAPG) (Ceppi et al., 2014) Tubulin Beta 1 Class VI (TUBB1), TUBB2A, TUBB2B, TUBB3, TUBB4) (Ceppi et al., 2014) and genes known to influence neurotoxicity sensitivity (i.e. CharcotMarie-Tooth disease confirmed in adults) have in the past been associated with vincristine toxicology (Kandula et al., 2016; Lee and Yang, 2017). A special attention is drawn to the CEP72 gene. In a past preliminary study with ALL children, genetic variants in the promotor region of CEP72 were associated with a higher risk of developing VIPN (Diouf et al., 2015). This investigation has recently been replicated in more studies. Seven recent studies investigated genetic variations in pharmacodynamics, microtubules stability, and neurotoxicity sensitivity. Two studies found an association with VIPN.

Gutierrez-Camino (2016) showed no significant association between VIPN and CEP72 (rs924607) in a retrospective Spanish cohort with 142 B-cell ALL patients. McClain et al. (2016) also found no significance with polymorphisms in the CEP72 gene, while Wright et al. (2019) showed that CEP72 (rs924607), SLC547 (rs1013940) (choline transporter), and Alpha Tocopherol Transfer Protein (TTPA, binding to vitamin E) (rs1050436) were significant associated with a higher risk of developing neuropathy. No association was found by Zgheib et al. (2018) between VIPN and CEP72 (rs924607), Ewing's tumor-associated antigen 1 (ETAA1) (rs17032980) and Melatonin Receptor 1B (MTNR1B) (rs12786200).

Li et al. (2019) investigated two independent cohorts and used a meta-analysis to assess the association between multiple SNPs and VIPN. One SNP, rs1045644 (encoding for protein cochlin, which is associated with progressive hearing loss and vestibular imbalance), showed a protective effect against neuropathy, while rs7963521 (gene involved in angiogenesis) was associated with a higher risk of VIPN. Martin-Guerrero et al. (2019) used a retrospective cohort with $152 \mathrm{~B}$-cell ALL patients to analyze 24 polymorphisms (in TUBB1, TUBB2A, TUBB2B, TUBB3, TUBB4, MAPT, MIR146a, MIR202, and MIR411). Before adjusting for false discovery rate, several gene variants have been associated with vincristine-induced neurotoxicity. Patients carrying MAPT (rs11867549), Mir-202 (rs12355840), and TUBB3 (rs4395073) had a higher risk of developing neurotoxicity. Also several haplotypes were associated with neurotoxicity.

Abaji et al. (2018) screened retrospectively WES data of ALL patients to find possible new gene variants which could be associated with VIPN. In this study, three new gene variants are association with VIPN: Spectrin Repeat Containing Nuclear Envelope Protein 2 (SYNE2) (rs2781377), Mitochondrial Ribosomal Protein L47 (MRPL47) (rs10513762) and Bromo Adjacent Homology Domain Containing 1 (BAHD1) (rs3803357). While SYNE2 (rs2781377) and MRPL47 (rs10513762) were associated with a higher risk of developing VIPN, BAHD1 (rs3803357) showed a protective effect. SYNE2 is a protein involved in cellular cytoskeletons, DNA damage repair and other cellular processes. MRPL47 plays a role in the mitochondrial protein synthesis. BAHD1 is a protein involved in gene silencing
Studies investigated polymorphisms in metabolism, transport, pharmacodynamics, and sensitivity genes of patients to VIPN shows conflicting results. While CEP72 has drawn more attention, its role has yet to be confirmed. The new gene variants associated with VIPN showed by Abaji et al. needs to be replicated by other studies to include these gene variants as risk factors for developing VIPN.

\section{DISCUSSION}

Chemotherapeutics are known for their narrow therapeutic window. While it is of utmost importance to use the right dose to sustain a favorable outcome in pediatric oncology, toxic doses cause poor outcomes, and a worse quality of life for pediatric cancer survivors. Based upon inter-individual differences in occurrence and severity of toxicity between pediatric cancer patients, the need for personalized treatment is apparent. PGx has been introduced to understand and facilitate individual treatments in pediatric oncology.

With this review, we present new developments over the past years concerning PGx within pediatric oncology. We included relevant literature from 2016 onward, revealing new genetic variations as well as new evidence for already known associated genetic variations with chemotherapeutics' toxicity.

Most studies have focused on genetic variations within metabolism or transport genes. Surprisingly, while CYP enzymes influence drug exposure significantly within other drug categories [e.g. selective serotonin reuptake inhibitors (Relling et al., 2020)], associations with toxicities of alkylating agents, anthracyclines, topoisomerase inhibitors and vinca alkaloids were not consistently found in studies included in this review. $\mathrm{ABC}$ transporters play a role in the transport of anthracyclines, methotrexate, platinum compounds, glucocorticosteroids, thiopurines, topoisomerase inhibitors, and vinca alkaloids. SLC transporters are thought to play a role in the transport of anthracyclines, asparaginase, methotrexate, topoisomerase inhibitors, and vinca alkaloids. However, there is slight evidence for robust and reproducible correlations between transporter genes and efficacy or toxicity of chemotherapeutics.

The role of ontogeny in the activity of metabolic enzymes or transporters may play a part when studying patient populations of different age groups, especially in neonates and infants (Mlakar et al., 2016). In our review, we focused on pediatric populations but found no indication that (young) age was considered an independent factor that influences the role of PGx in toxicity of chemotherapeutic drugs. However, neonates and infants are underrepresented in pediatric oncology studies, because of limited occurrence of malignancies in these age groups. Strong evidence for associations between genetic variations in NUDT15 and TPMT and 6MP toxicity have been confirmed in our review and preemptive genetic testing for NUDT15 and TPMT variants should be implemented in standard clinical care. Future attention should be focused on standardizing corresponding dosing guidelines and exploring the relevance of less frequent occurring variants of TPMT and 
NUDT15. Evidence has been established for the role of UGT1A1 polymorphisms in irinotecan toxicity in adults, but this still need confirmation in pediatric populations.

Due to improvements in genomic sequencing technologies, research has shifted to genetic variations in pharmacodynamics and cytostatic targets as well as less apparent gene polymorphisms as an explanation for efficacy or toxicity differences of chemotherapeutics in pediatric cancer patients. Variations in genes coding for cytostatic targets (e.g. microtubule stabilization by VCR, glucocorticoid sensitivity, folate activity by MTX) have been included in this review and showed probable contribution to individual differences in response and toxicity. However, there were no decisive conclusions that could be drawn from these studies and recommendations on dose adjustments are not yet established.

We did not include studies on immunotherapy or supportive care drugs. The use of immunotherapy in pediatric oncology has increased in the past years, showing promising results. However, as with chemotherapeutics, individual differences in response and toxicity of immunotherapy within children are reported. In future years, the role of genetics will need to be further elucidated. Supportive care drugs are also of great importance in limiting chemotherapeutics' toxicities (e.g. neuropathy, diarrhea, infections due to neutropenia). Therefore, optimalization of supportive care dosages is needed and PGx may be beneficial in assessing the correct dosages. Currently, adult guidelines are used to assess the impact of PGx in dosing supportive care drugs in pediatric oncology.

Our review shows that pharmacogenomics in pediatric oncology is still facing challenges. The main problem is inconsistency in results, caused by small population sizes, differences in (statistical) interpretation, variations in sequencing technologies as well as in differences in definition of clinical outcomes. Lack of information on how to use genetic test results

\section{REFERENCES}

Abaji, R., and Krajinovic, M. (2016). Current perspective on pediatric pharmacogenomics. Expert Opin. Drug Metab. Toxicol. 12 (4), 363-365. doi: $10.1517 / 17425255.2016 .1145656$

Abaji, R., Gagne, V., Xu, C. J., Spinella, J. F., Ceppi, F., Laverdiere, C., et al. (2017). Whole-exome sequencing identified genetic risk factors for asparaginaserelated complications in childhood ALL patients. Oncotarget 8 (27), 4375243767. doi: 10.18632/oncotarget.17959

Abaji, R., Ceppi, F., Patel, S., Gagné, V., Xu, C. J., Spinella, J. F., et al. (2018). Genetic risk factors for VIPN in childhood acute lymphoblastic leukemia patients identified using whole-exome sequencing. Pharmacogenomics 19 (15), 1181-1193. doi: 10.2217/pgs-2018-0093

Aminkeng, F., Bhavsar, A. P., Visscher, H., Rassekh, S. R., Li, Y., Lee, J. W., et al. (2015). A coding variant in RARG confers susceptibility to anthracyclineinduced cardiotoxicity in childhood cancer. Nat. Genet. 47 (9), 1079-1084. doi: 10.1038/ng.3374

Aminkeng, F., Ross, C. J., Rassekh, S. R., Hwang, S., Rieder, M. J., Bhavsar, A. P., et al. (2016). Recommendations for genetic testing to reduce the incidence of anthracycline-induced cardiotoxicity. Br. J. Clin. Pharmacol. 82 (3), 683-695. doi: $10.1111 /$ bcp. 13008

Anthracyclines and related substances (2020). PharmGKB (Accessed on Januari 07, 2020). Available from: https://www.pharmgkb.org/chemical/PA130620651.

Armenian, S. H., Ding, Y., Mills, G., Sun, C., Venkataraman, K., Wong, F. L., et al. (2013). Genetic susceptibility to anthracycline-related congestive heart failure to adjust the use or dose of chemotherapeutics hinders broad introduction in clinical practice (Relling et al., 2020). Also, pediatric cancer patients receive combinations of chemotherapeutics, making it difficult to discern the impact of individual genetic variances. Finally, most studies are performed in pediatric ALL patients, leading to limited data on other pediatric cancer types.

In conclusion, pharmacogenomics of chemotherapeutics is complex with multiple genes involved in the process of metabolism, transport and its target mechanisms. Future studies should focus on establishing comprehensive models, integrating pharmacogenomics with pharmacokinetics and pharmacodynamics data to aid dosing guidelines. Standardization of clinical outcome data and toxicity definitions within electronic health records combined with the increased availability of genomic sequences techniques in clinical practice will help to validate these models in larger populations.

\section{AUTHOR CONTRIBUTIONS}

EB developed the search codes (with libraries from Utrecht University Library) for the databases and collected the data. All authors reviewed the results and contributed to the manuscript. All authors contributed to the article and approved the submitted version.

\section{SUPPLEMENTARY MATERIAL}

The Supplementary Material for this article can be found online at: https://www.frontiersin.org/articles/10.3389/fphar.2020. 01184/full\#supplementary-material in survivors of haematopoietic cell transplantation. Br. J. Haematol. 163 (2), 205-213. doi: 10.1111/bjh.12516

Bansal, N., Amdani, S., Lipshultz, E. R., and Lipshultz, S. E. (2017). Chemotherapy-induced cardiotoxicity in children. Expert Opin. Drug Metab. Toxicol. 13 (8), 817-832. doi: 10.1080/17425255.2017.1351547

Blanco, J. G., Leisenring, W. M., Gonzalez-Covarrubias, V. M., Kawashima, T. I., Davies, S. M., Relling, M. V., et al. (2008). Genetic polymorphisms in the carbonyl reductase 3 gene $\mathrm{CBR} 3$ and the $\mathrm{NAD}(\mathrm{P}) \mathrm{H}$ :quinone oxidoreductase 1 gene NQO1 in patients who developed anthracycline-related congestive heart failure after childhood cancer. Cancer 112 (12), 2789-2795. doi: 10.1002/ cncr.23534

Blanco, J. G., Sun, C. L., Landier, W., Chen, L., Esparza-Duran, D., Leisenring, W., et al. (2012). Anthracycline-related cardiomyopathy after childhood cancer: role of polymorphisms in carbonyl reductase genes-a report from the Children's Oncology Group. J. Clin. Oncol. 30 (13), 1415-1421. doi: 10.1200/ JCO.2011.34.8987

Brown, A. L., Foster, K. L., Lupo, P. J., Peckham-Gregory, E. C., Murray, J. C., Okcu, M. F., et al. (2017). DNA methylation of a novel PAK4 locus influences ototoxicity susceptibility following cisplatin and radiation therapy for pediatric embryonal tumors. Neuro-Oncology 19 (10), 1372-1379. doi: 10.1093/neuonc/nox076

Campbell, J. M., Bateman, E., Stephenson, M. D., Bowen, J. M., Keefe, D. M., and Peters, M. D. J. (2016). Methotrexate-induced toxicity pharmacogenetics: an umbrella review of systematic reviews and meta-analyses. Cancer Chemother. Pharmacol. 78 (1), 27-39. doi: 10.1007/s00280-016-3043-5 
Ceppi, F., Langlois-Pelletier, C., Gagné, V., Rousseau, J., Ciolino, C., De Lorenzo, S., et al. (2014). Polymorphisms of the vincristine pathway and response to treatment in children with childhood acute lymphoblastic leukemia. Pharmacogenomics 15 (8), 1105-1116. doi: 10.2217/pgs.14.68

Chang, V. Y., and Wang, J. J. (2018). Pharmacogenetics of Chemotherapy-Induced Cardiotoxicity. Curr. Oncol. Rep. 20 (7), 52. doi: 10.1007/s11912-018-0696-8

Chang, C., Hu, Y., Hogan, S. L., Mercke, N., Gomez, M., O’Bryant, C., et al. (2017). Pharmacogenomic Variants May Influence the Urinary Excretion of Novel Kidney Injury Biomarkers in Patients Receiving Cisplatin. Int. J. Mol. Sci. 18 (7), 1333. doi: 10.3390/ijms18071333

Chiengthong, K., Ittiwut, C., Muensri, S., Sophonphan, J., Sosothikul, D., Seksan, P., et al. (2016). NUDT15 c.415C $>\mathrm{T}$ increases risk of 6-mercaptopurine induced myelosuppression during maintenance therapy in children with acute lymphoblastic leukemia. Haematologica 101 (1), e24-e26. doi: 10.3324/ haematol.2015.134775

Choi, R., Sohn, I., Kim, M. J., Woo, H. I., Lee, J. W., Ma, Y., et al. (2019). Pathway genes and metabolites in thiopurine therapy in Korean children with acute lymphoblastic leukaemia. Br. J. Clin. Pharmacol. 85 (7), 1585-1597. doi: 10.1111/bcp.13943

Conyers, R., Devaraja, S., and Elliott, D. (2018). Systematic review of pharmacogenomics and adverse drug reactions in paediatric oncology patients. Pediatr. Blood Cancer 65 (4), 1-12. doi: 10.1002/pbc.26937

CYP2B6 P (2020). PharmVar (Accessed on June 20, 2020). Available from: https:// www.pharmvar.org/haplotype/744.

Diouf, B., Crews, K. R., Lew, G., Pei, D., Cheng, C., Bao, J., et al. (2015). Association of an inherited genetic variant with vincristine-related peripheral neuropathy in children with acute lymphoblastic leukemia. Jama 313 (8), 815-823. doi: 10.1001/jama.2015.0894

Dolan, M. E., El Charif, O., Wheeler, H. E., Gamazon, E. R., Ardeshir-RouhaniFard, S., Monahan, P., et al. (2017). Clinical and Genome-Wide Analysis of Cisplatin-Induced Peripheral Neuropathy in Survivors of Adult-Onset Cancer. Clin. Cancer Res. Off. J. Am. Assoc. Cancer Res. 23 (19), 5757-5768. doi: 10.1158/1078-0432.CCR-16-3224

Doxorubicin Pathway (Cardiomyocyte Cell) P (2020). PharmGKB (Accessed Acessed on June 20, 2020). Available from: https://www.pharmgkb.org/ pathway/PA165292164.

Doxorubicin Pathway, P. (2020). PharmGKB (Accessed Acessed on June 20, 2020). Available from: https://www.pharmgkb.org/pathway/PA165292177.

Duflot, T., Marie-Cardine, A., Verstuyft, C., Filhon, B., Pereira, T., MassyGuillemant, N., et al. (2018). Possible role of CYP2B6 genetic polymorphisms in ifosfamide-induced encephalopathy: report of three cases. Fundam. Clin. Pharmacol. 32 (3), 337-342. doi: 10.1111/fcp.12345

Edwardson, D. W., Narendrula, R., Chewchuk, S., Mispel-Beyer, K., Mapletoft, J. P., and Parissenti, A. M. (2015). Role of Drug Metabolism in the Cytotoxicity and Clinical Efficacy of Anthracyclines. Curr. Drug Metab. 16 (6), 412-426. doi: 10.2174/1389200216888150915112039

Eipel, O., Hegyi, M., Csordás, K., Németh, K., Luczay, A., Török, D., et al. (2016). Some GCR polymorphisms (N363S, ER22/23EK, and Bcl-1) may influence steroid-induced toxicities and survival rates in children with ALL. J. Pediatr. Hematol. 38 (5), 334-340. doi: 10.1097/MPH.0000000000000535

ElFayoumi, R. I., Hagras, M. M., Abozenadaha, A., Gari, M., Abosoudah, I., Shinawi, T., et al. (2018). The influence of polymorphisms in the drug transporter, ABCB1 on the toxicity of glucocorticoids in Saudi children with acute lymphoblastic leukaemia. Pharmacol. Rep. 71 (1), 90-95. doi: 10.1016/ j.pharep.2018.09.010

Etienne-Grimaldi, M.-C., Boyer, J.-C., Thomas, F., Quaranta, S., Picard, N., Loriot, M.-A., et al. (2015). UGT1A1 genotype and irinotecan therapy: general review and implementation in routine practice. Fundam. Clin. Pharmacol. 29 (3), 219-237. doi: 10.1111/fcp.12117

Finkelstein, Y., Blonquist, T. M., Vijayanathan, V., Stevenson, K. E., Neuberg, D. S., Silverman, L. B., et al. (2017). A thymidylate synthase polymorphism is associated with increased risk for bone toxicity among children treated for acute lymphoblastic leukemia. Pediatr. Blood Cancer 64 (7), 1-9. doi: 10.1002/pbc.26393

Franca, R., Rebora, P., Bertorello, N., Fagioli, F., Conter, V., Biondi, A., et al. (2017). Pharmacogenetics and induction/consolidation therapy toxicities in acute lymphoblastic leukemia patients treated with AIEOP-BFM ALL 2000 protocol. Pharmacogenom. J. 17 (1), 4-10. doi: 10.1038/tpj.2015.83
Franca, R., Stocco, G., Favretto, D., Giurici, N., del Rizzo, I., Locatelli, F., et al. (2019). PACSIN2 rs2413739 influence on thiopurine pharmacokinetics: validation studies in pediatric patients. Pharmacogenom. J. 20, 415-425. doi: 10.1038/s41397-019-0130-0

Gagne, V., St-Onge, P., Beaulieu, P., Laverdiere, C., Leclerc, J. M., Tran, T. H., et al. (2020). HLA alleles associated with asparaginase hypersensitivity in childhood ALL: a report from the DFCI Consortium. Pharmacogenomics 21 (8), 541-547. doi: $10.2217 /$ pgs-2019-0195

Gerbek, T., Ebbesen, M., Nersting, J., Frandsen, T. L., Appell, M. L., and Schmiegelow, K. (2018). Role of TPMT and ITPA variants in mercaptopurine disposition. Cancer Chemother. Pharmacol. 81 (3), 579-586. doi: 10.1007/s00280-018-3525-8

Gervasini, G., de Murillo, S. G., Jimenez, M., de la Maya, M. D., and Vagace, J. M. (2017). Effect of polymorphisms in transporter genes on dosing, efficacy and toxicity of maintenance therapy in children with acute lymphoblastic leukemia. Gene 628, 72-77. doi: 10.1016/j.gene.2017.07.025

Girard, P., Auquier, P., Barlogis, V., Contet, A., Poiree, M., Demeocq, F., et al. (2013). Symptomatic osteonecrosis in childhood leukemia survivors: prevalence, risk factors and impact on quality of life in adulthood. Haematologica 98 (7), 1089-1097. doi: 10.3324/haematol.2012.081265

Gutierrez-Camino, A., Martin-Guerrero, I., Lopez-Lopez, E., Echebarria-Barona, A., Zabalza, I., Ruiz, I., et al. (2016). Lack of association of the CEP72 RS924607 TT genotype with vincristine-related peripheral neuropathy during the early phase of pediatric acute lymphoblastic leukemia treatment in a Spanish population. Pharmacogenet. Genomics 26 (2), 100-102. doi: 10.1097/ FPC.0000000000000191

Gutierrez-Camino, A., Umerez, M., Martin-Guerrero, I., Garcia de Andoin, N., Santos, B., Sastre, A., et al. (2017a). Mir-pharmacogenetics of Vincristine and peripheral neurotoxicity in childhood B-cell acute lymphoblastic leukemia. Pharmacogenom. J. 18 (6), 704-712. doi: 10.1038/s41397-017-0003-3

Guttierez-Camino, A., Oosterom, N., Den Hoed, M. A., Lopez-Lopez, E., MartinGuerrero, I., Pluijm, S. M., et al. (2017b). The miR-1206 microRNA variant is associated with methotrexate-induced oral mucositis in pediatric acute lymphoblastic leukemia. Pharmacogenet Genomics. 27 (8), 303-306. doi: 10.1097/FPC.0000000000000291

Haidar, C. E., Relling, M. V., and Hoffman, J. M. (2019). Preemptively Precise: Returning and Updating Pharmacogenetic Test Results to Realize the Benefits of Preemptive Testing. Clin. Pharmacol. Ther. 106 (5), 942-944. doi: 10.1002/ cpt.1613

Hattinger, C. M., Biason, P., Iacoboni, E., Gagno, S., Fanelli, M., Tavanti, E., et al. (2016). Candidate germline polymorphisms of genes belonging to the pathways of four drugs used in osteosarcoma standard chemotherapy associated with risk, survival and toxicity in non-metastatic high-grade osteosarcoma. Oncotarget 7 (38), 61970-61987. doi: 10.18632/oncotarget. 11486

Hegyi, M., Arany, A., Semsei, A. F., Csordas, K., Eipel, O., Gezsi, A., et al. (2017). Pharmacogenetic analysis of high-dose methotrexate treatment in children with osteosarcoma. Oncotarget 8 (6), 9388-9398. doi: 10.18632/ oncotarget. 11543

Helsby, N. A., Hui, C.-Y., Goldthorpe, M. A., Coller, J. K., Soh, M. C., Gow, P. J., et al. (2010). The combined impact of CYP2C19 and CYP2B6 pharmacogenetics on cyclophosphamide bioactivation. Br. J. Clin. Pharmacol. 70 (6), 844-853. doi: 10.1111/j.1365-2125.2010.03789.x

Hesse, L. M., He, P., Krishnaswamy, S., Hao, Q., Hogan, K., von Moltke, L. L., et al. (2004). Pharmacogenetic determinants of interindividual variability in bupropion hydroxylation by cytochrome P450 2B6 in human liver microsomes. Pharmacogenetics 14 (4), 225-238. doi: 10.1097/00008571200404000-00002

Hijiya, N., and van der Sluis, I. M. (2016). Asparaginase-associated toxicity in children with acute lymphoblastic leukemia. Leukemia Lymphoma 57 (4), 748757. doi: 10.3109/10428194.2015.1101098

Hildebrandt, T. M. A. T., Reyes, M., Wu, X., Pu, X., Thompson, K. A., Ma, J., et al. (2017). Hypertension Susceptibility Loci are Associated with Anthracyclinerelated Cardiotoxicity in Long-term Childhood Cancer Survivors. Sci. Rep. 7 (1), 9698. doi: 10.1038/s41598-017-09517-2

Hojfeldt, S. G., Wolthers, B. O., Tulstrup, M., Abrahamsson, J., Gupta, R., HarilaSaari, A., et al. (2019). Genetic predisposition to PEG-asparaginase 
hypersensitivity in children treated according to NOPHO ALL2008. Br. J. Haematol. 184 (3), 405-417. doi: 10.1111/bjh.15660

Huang, Z., Wang, J., Qian, J., Li, Y., Xu, Z., Chen, M., et al. (2017). Effects of cytochrome P450 family 3 subfamily a member 5 gene polymorphisms on daunorubicin metabolism and adverse reactions in patients with acute leukemia. Mol. Med. Rep. 15 (6), 3493-3498. doi: 10.3892/mmr.2017.6470

Jimenez-Morales, S., Ramirez-Florencio, M., Mejia-Arangure, J. M., NunezEnriquez, J. C., Bekker-Mendez, C., Torres-Escalante, J. L., et al. (2016). Analysis of Thiopurine S-Methyltransferase Deficient Alleles in Acute Lymphoblastic Leukemia Patients in Mexican Patients. Arch. Med. Res. 47 (8), 615-622. doi: 10.1016/j.arcmed.2016.11.018

Kandula, T., Park, S. B., Cohn, R. J., Krishnan, A. V., and Farrar, M. A. (2016). Pediatric chemotherapy induced peripheral neuropathy: A systematic review of current knowledge. Cancer Treat Rev. 50, 118-128. doi: 10.1016/ j.ctrv.2016.09.005

Karol, S. E., Yang, W., Van Driest, S. L., Chang, T. Y., Kaste, S., Bowton, E., et al. (2015). Genetics of glucocorticoid-associated osteonecrosis in children with acute lymphoblastic leukemia. Blood 126 (15), 1770-1776. doi: 10.1182/blood2015-05-643601

Khera, S., Trehan, A., Bhatia, P., Singh, M., Bansal, D., and Varma, N. (2019). Prevalence of TPMT, ITPA and NUDT 15 genetic polymorphisms and their relation to 6MP toxicity in north Indian children with acute lymphoblastic leukemia. Cancer Chemother. Pharmacol. 83 (2), 341-348. doi: 10.1007/ s00280-018-3732-3

Khrunin, A. V., Moisseev, A., Gorbunova, V., and Limborska, S. (2010). Genetic polymorphisms and the efficacy and toxicity of cisplatin-based chemotherapy in ovarian cancer patients. Pharmacogenom. J. 10 (1), 54-61. doi: 10.1038/tpj.2009.45

Khrunin, A. V., Khokhrin, D. V., Moisseev, A. A., Gorbunova, V. A., and Limborska, S. A. (2014). Pharmacogenomic assessment of cisplatin-based chemotherapy outcomes in ovarian cancer. Pharmacogenomics 15 (3), 329337. doi: $10.2217 /$ pgs. 13.237

Kim, H., Seo, H., Park, Y., Min, B. J., Seo, M. E., Park, K. D., et al. (2018). APEX1 Polymorphism and Mercaptopurine-Related Early Onset Neutropenia in Pediatric Acute Lymphoblastic Leukemia. Cancer Res. Treat 50 (3), 823-834. doi: $10.4143 /$ crt.2017.351

KNMP apothekersorganisatie (2020). Pharmacogenetics (Accessed Accesed on December 01, 2019). Available from: https://www.knmp.nl/patientenzorg/ medicatiebewaking/farmacogenetica/pharmacogenetics-1.

Kotnik, B. F., Jazbec, J., Grabar, P. B., Rodriguez-Antona, C., and Dolzan, V. (2017). Association between SLC19A1 gene polymorphism and high dose methotrexate toxicity in childhood acute lymphoblastic leukaemia and non Hodgkin malignant lymphoma: Introducing a haplotype based approach. Radiol. Oncol. 51 (4), 455-462. doi: 10.1515/raon-2017-0040

Koutsilieri, S., Caudle, K. E., Alzghari, S. K., Monte, A. A., Relling, M. V., and Patrinos, G. P. (2019). Optimizing thiopurine dosing based on TPMT and NUDT15 genotypes: It takes two to tango. Am. J. Hematol. 94 (7), 737-740. doi: 10.1002/ajh.25485

Krajinovic, M., Elbared, J., Drouin, S., Bertout, L., Rezgui, A., Ansari, M., et al. (2016). Polymorphisms of ABCC5 and NOS3 genes influence doxorubicin cardiotoxicity in survivors of childhood acute lymphoblastic leukemia. Pharmacogenom. J. 16 (6), 530-535. doi: 10.1038/tpj.2015.63

Kutszegi, N., Yang, X., Gézsi, A., Schermann, G., Erdélyi, D. J., Semsei, Á. F., et al. (2017). HLA-DRB1*07:01-HLA-DQA1*02:01-HLA-DQB1*02:02 haplotype is associated with a high risk of asparaginase hypersensitivity in acute lymphoblastic leukemia. Haematologica 102 (9), 1578-1586. doi: 10.3324/ haematol.2017.168211

Lamba, V., Panetta, J. C., Strom, S., and Schuetz, E. G. (2010). Genetic Predictors of Interindividual Variability in Hepatic CYP3A4 Expression. J. Pharmacol. Exp. Ther. 332 (3), 1088. doi: 10.1124/jpet.109.160804

Lang, T., Klein, K., Fischer, J., Nüssler, A. K., Neuhaus, P., Hofmann, U., et al. (2001). Extensive genetic polymorphism in the human CYP2B6 gene with impact on expression and function in human liver. Pharmacogenetics 11 (5), 399-415. doi: 10.1097/00008571-200107000-00004

Lee, S. H. R., and Yang, J. J. (2017). Pharmacogenomics in acute lymphoblastic leukemia. Best Pract. Res. Clin. Haematol. 30 (3), 229-236. doi: 10.1016/ j.beha.2017.07.007
Li, L., Sajdyk, T., Smith, E. M. L., Chang, C. W., Li, C., Ho, R. H., et al. (2019). Genetic Variants Associated With Vincristine-Induced Peripheral Neuropathy in Two Populations of Children With Acute Lymphoblastic Leukemia. Clin. Pharmacol. Ther. 105 (6), 1421-1428. doi: 10.1002/cpt.1324

Liang, D. C., Yang, C. P., Liu, H. C., Jaing, T. H., Chen, S. H., Hung, I. J., et al. (2016). NUDT15 gene polymorphism related to mercaptopurine intolerance in Taiwan Chinese children with acute lymphoblastic leukemia. Pharmacogenom. J. 16 (6), 536-539. doi: 10.1038/tpj.2015.75

Liberman, P. H. P., Goffi-Gomez, M. V. S., Schultz, C., Jacob, P. L., de Paula, C. A. A., Sartorato, E. L., et al. (2018). Contribution of the GSTP1 c.313A>G variant to hearing loss risk in patients exposed to platin chemotherapy during childhood. Clin. Transl. Oncol. 21 (5), 630-635. doi: 10.1007/s12094-018-1964-7

Lin, Y. J., Chang, J. S., Liu, X., Hung, C. H., Lin, T. H., Huang, S. M., et al. (2013). Association between GRIN3A gene polymorphism in Kawasaki disease and coronary artery aneurysms in Taiwanese children. PloS One 8 (11), e81384. doi: 10.1371/journal.pone.0081384

Liu, C., Yang, W., Devidas, M., Cheng, C., Pei, D., Smith, C., et al. (2016). Clinical and Genetic Risk Factors for Acute Pancreatitis in Patients With Acute Lymphoblastic Leukemia. J. Clin. Oncol. 34 (18), 2133-2140. doi: 10.1200/ JCO.2015.64.5812

Liu, Y., Fernandez, C. A., Smith, C., Yang, W., Cheng, C., Panetta, J. C., et al. (2017). Genome-Wide Study Links PNPLA3 Variant With Elevated Hepatic Transaminase After Acute Lymphoblastic Leukemia Therapy. Clin. Pharmacol. Ther. 102 (1), 131-140. doi: 10.1002/cpt.629

Liu, S. G., Gao, C., Zhang, R. D., Zhao, X. X., Cui, L., Li, W. J., et al. (2017). Polymorphisms in methotrexate transporters and their relationship to plasma methotrexate levels, toxicity of high-dose methotrexate, and outcome of pediatric acute lymphoblastic leukemia. Oncotarget 8 (23), 37761-37772. doi: 10.18632/oncotarget.17781

Lopez-Lopez, E., Gutierrez-Camino, A., Astigarraga, I., Navajas, A., EchebarriaBarona, A., Garcia-Miguel, P., et al. (2016). Vincristine pharmacokinetics pathway and neurotoxicity during early phases of treatment in pediatric acute lymphoblastic leukemia. Pharmacogenomics 17 (7), 731-741. doi: $10.2217 /$ pgs-2016-0001

Lopez-Santillan, M., Iparraguirre, L., Martin-Guerrero, I., Gutierrez-Camino, A., and Garcia-Orad, A. (2017). Review of pharmacogenetics studies of Lasparaginase hypersensitivity in acute lymphoblastic leukemia points to variants in the GRIA1 gene. Drug Metab. Pers. Ther. 32 (1), 1-9. doi: 10.1515/dmpt-2016-0033

Mahmoud, L. B., Mdhaffar, M., Frikha, R., Ghozzi, H., Hakim, A., Sahnoun, Z., et al. (2018). Use of MTHFR C677T polymorphism and plasma pharmacokinetics to predict methotrexate toxicity in patients with acute lymphoblastic leukemia. $A d v$. Clin. Exp. Med. 27 (8), 1061-1068. doi: 10.17219/acem/69802

Martin-Guerrero, I., Gutierrez-Camino, A., Echebarria-Barona, A., Astigarraga, I., Garcia de Andoin, N., Navajas, A., et al. (2019). Variants in vincristine pharmacodynamic genes involved in neurotoxicity at induction phase in the therapy of pediatric acute lymphoblastic leukemia. Pharmacogenom. J. 19 (6), 564-569. doi: 10.1038/s41397-019-0081-5

Mattano, L. A.Jr., Sather, H. N., Trigg, M. E., and Nachman, J. B. (2000). Osteonecrosis as a complication of treating acute lymphoblastic leukemia in children: a report from the Children's Cancer Group. J. Clin. Oncol. 18 (18), 3262-3272. doi: 10.1200/JCO.2000.18.18.3262

McClain, C. A., Bernhardt, M. B., Berger, A., Winslow, R., Scheurer, M. E., and Schafer, E. S. (2016). Pharmacogenomic association with neurotoxicity in hispanic children with acute lymphoblastic leukemia (ALL). Blood 128 (22), 684-687. doi: 10.1182/blood.V128.22.3962.3962

McGowan, J. V., Chung, R., Maulik, A., Piotrowska, I., Walker, J. M., and Yellon, D. M. (2017). Anthracycline Chemotherapy and Cardiotoxicity. Cardiovasc. Drugs Ther. 31 (1), 63-75. doi: 10.1007/s10557-016-6711-0

Methotrexate Pathway, P. (2020). PharmGKB (Accessed Accesed on June 20, 2020). Available from: https://www.pharmgkb.org/pathway/PA165816349.

Mikkelsen, T. S., Thorn, C. F., Yang, J. J., Ulrich, C. M., French, D., Zaza, G., et al. (2011). PharmGKB summary: methotrexate pathway. Pharmacogenet. Genomics 21 (10), 679-686. doi: 10.1097/FPC.0b013e328343dd93

Milosevic, G., Kotur, N., Krstovski, N., Lazic, J., Zukic, B., Stankovic, B., et al. (2018). Variants in TPMT, ITPA, ABCC4 and ABCB1 Genes As Predictors 
of 6-mercaptopurine Induced Toxicity in Children with Acute Lymphoblastic Leukemia. J. Med. Biochem. 37 (3), 320-327. doi: 10.1515/jomb-2017-0060

Miyoshi, Y., Ando, A., Takamura, Y., Taguchi, T., Tamaki, Y., and Noguchi, S. (2002). Prediction of response to docetaxel by CYP3A4 mRNA expression in breast cancer tissues. Int. J. Cancer. 97 (1), 129-132. doi: 10.1002/ijc.1568

Mlakar, V., Curtis, P. H. D., Uppugunduri, C. R. S., Krajinovic, M., and Ansari, M. (2016). Pharmacogenomics in pediatric oncology: Review of gene-drug associations for clinical use. Int. J. Mol. Sci. 17 (9), 1-34. doi: 10.3390/ ijms17091502

Mora, E., Smith, E. M., Donohoe, C., and Hertz, D. L. (2016). Vincristine-induced peripheral neuropathy in pediatric cancer patients. Am. J. Cancer Res. 6 (11), 2416-2430.

Moriyama, T., Nishii, R., Perez-Andreu, V., Yang, W., Klussmann, F. A., Zhao, X., et al. (2016). NUDT15 polymorphisms alter thiopurine metabolism and hematopoietic toxicity. Nat. Genet. 48 (4), 367-373. doi: 10.1038/ng.3508

Moriyama, T., Yang, Y. L., Nishii, R., Ariffin, H., Liu, C., Lin, T. N., et al. (2017). Novel variants in NUDT15 and thiopurine intolerance in children with acute lymphoblastic leukemia from diverse ancestry. Blood 130 (10), 1209-1212. doi: 10.1182/blood-2017-05-782383

Moriyama, T., Nishii, R., Lin, T. N., Kihira, K., Toyoda, H., Jacob, N., et al. (2017). The effects of inherited NUDT15 polymorphisms on thiopurine active metabolites in Japanese children with acute lymphoblastic leukemia. Pharmacogenet. Genomics 27 (6), 236-239. doi: 10.1097/FPC.0000 000000000282

Moudi, M., Go, R., Yien, C. Y. S., and Nazre, M. (2013). Vinca alkaloids. Int. J. Prev. Med. 4 (11), 1231-1235.

Myers, A. L., Kawedia, J. D., Champlin, R. E., Kramer, M. A., Nieto, Y., Ghose, R., et al. (2017). Clarifying busulfan metabolism and drug interactions to support new therapeutic drug monitoring strategies: a comprehensive review. Expert Opin. Drug Metab. Toxicol. 13 (9), 901-923. doi: 10.1080/17425255. 2017.1360277

Nava, T., Kassir, N., Rezgui, M. A., Uppugunduri, C. R. S., Huezo-Diaz Curtis, P., Duval, M., et al. (2018). Incorporation of GSTA1 genetic variations into a population pharmacokinetic model for IV busulfan in paediatric hematopoietic stem cell transplantation. Br. J. Clin. Pharmacol. 84 (7), 14941504. doi: 10.1111/bcp.13566

Nishikawa, T., Yamaguchi, H., Ikawa, K., Nakayama, K., Higashi, E., Miyahara, E., et al. (2019). Influence of GST polymorphisms on busulfan pharmacokinetics in Japanese children. Pediatr. Int. 61 (6), 558-565. doi: 10.1111/ped.13859

Olkku, A., Bodine, P., Linnala-Kankkunen, A., and Mahonen, A. (2004). Glucocorticoids induce glutamine synthetase expression in human osteoblastic cells: A novel observation in bone. Bone 34, 320-329. doi: 10.1016/j.bone.2003.09.010

O’Leary, M., Krailo, M., Anderson, J. R., Reaman, G. H., and Children's Oncology, G. (2008). Progress in childhood cancer: 50 years of research collaboration, a report from the Children's Oncology Group. Semin. Oncol. 35 (5), 484-493. doi: 10.1053/j.seminoncol.2008.07.008

Park, J. A., and Shin, H. Y. (2016). Influence of genetic polymorphisms in the folate pathway on toxicity after high-dose methotrexate treatment in pediatric osteosarcoma. Blood Res. 51 (1), 50-57. doi: 10.5045/br.2016.51.1.50

Park, S. B., Goldstein, D., Krishnan, A. V., Lin, C. S. Y., Friedlander, M. L., Cassidy, J., et al. (2013). Chemotherapy-induced peripheral neurotoxicity: a critical analysis. CA Cancer J. Clin. 63 (6), 419-437. doi: 10.3322/caac.21204

Platinum Pathway Pharmacokinetics/Pharmacodynamics (2020). PharmGKB (Accessed on December 15, 2019). Available from: https://www.pharm gkb.org/pathway/PA150642262.

Plesa, M., Gagné, V., Glisovic, S., Younan, M., Sharif-Askari, B., Laverdière, C., et al. (2019). Influence of BCL2L11 polymorphism on osteonecrosis during treatment of childhood acute lymphoblastic leukemia. Pharmacogenom. J. 19 (1), 33-41. doi: 10.1038/s41397-017-0002-4

Pui, C.-H., Gajjar, A. J., Kane, J. R., Qaddoumi, I. A., and Pappo, A. S. (2011). Challenging issues in pediatric oncology. Nat. Rev. Clin. Oncol. 8 (9), 540-549. doi: 10.1038/nrclinonc.2011.95

Rajić, V., Aplenc, R., Debeljak, M., Prestor, V. V., Karas-Kuzelicki, N., MlinaricRascan, I., et al. (2009). Influence of the polymorphism in candidate genes on late cardiac damage in patients treated due to acute leukemia in childhood. Leuk. Lymphoma 50 (10), 1693-1698. doi: 10.1080/10428190903177212
Ramírez-Pacheco, A., Moreno-Guerrero, S., Alamillo, I., Medina-Sanson, A., Lopez, B., and Moreno-Galván, M. (2016). Mexican Childhood Acute Lymphoblastic Leukemia: A Pilot Study of the MDR1 and MTHFR Gene Polymorphisms and Their Associations with Clinical Outcomes. Genet. Test. Mol. Biomarkers 20 (10), 597-602. doi: 10.1089/gtmb.2015.0287

Rank, C. U., Wolthers, B. O., Grell, K., Albertsen, B. K., Frandsen, T. L., Overgaard, U. M., et al. (2019). Asparaginase-Associated Pancreatitis in Acute Lymphoblastic Leukemia: Results From the NOPHO ALL2008 Treatment of Patients 1-45 Years of Age. J. Clin. Oncol. 13, Jco1902208. doi: 10.1200/ JCO.19.02208

Razali, R. H., Noorizhab, M. N. F., Jamari, H., James, R. J., Teh, K. H., Ibrahim, H. M., et al. (2020). Association of ABCC2 with levels and toxicity of methotrexate in Malaysian Childhood Acute Lymphoblastic Leukemia (ALL). Pediatr. Hematol. Oncol. 37 (3), 185-197. doi: 10.1080/08880018.2019.1705949

Relling, M. V., and Klein, T. E. (2011). CPIC: Clinical Pharmacogenetics Implementation Consortium of the Pharmacogenomics Research Network. Clin. Pharmacol. Ther. 89 (3), 464-467. doi: 10.1038/clpt.2010.279

Relling, M. V., Schwab, M., Whirl-Carrillo, M., Suarez-Kurtz, G., Pui, C. H., Stein, C. M., et al. (2019). Clinical Pharmacogenetics Implementation Consortium Guideline for Thiopurine Dosing Based on TPMT and NUDT15 Genotypes: 2018 Update. Clin. Pharmacol. Ther. 105 (5), 1095-1105. doi: $10.1002 / \mathrm{cpt} .1304$

Relling, M. V., Klein, T. E., Gammal, R. S., Whirl-Carrillo, M., Hoffman, J. M., and Caudle, K. E. (2020). The Clinical Pharmacogenetics Implementation Consortium: 10 Years Later. Clin. Pharmacol. Ther. 107 (1), 171-175. doi: 10.1002/cpt.1651

Robinson, K. M., Yang, W., Karol, S. E., Kornegay, N., Jay, D., Cheng, C., et al. (2019). No evidence that G6PD deficiency affects the efficacy or safety of daunorubicin in acute lymphoblastic leukemia induction therapy. Pediatr. Blood Cancer 66 (6), 1-5. doi: 10.1002/pbc.27681

Roden, D. M., McLeod, H. L., Relling, M. V., Williams, M. S., Mensah, G. A., Peterson, J. F., et al. (2019). Pharmacogenomics. Lancet 394 (10197), 521-532. doi: 10.1016/S0140-6736(19)31276-0

Ross, C. J. D., Katzov-Eckert, H., Dubé, M.-P., Brooks, B., Rassekh, S. R., Barhdadi, A., et al. (2009). Genetic variants in TPMT and COMT are associated with hearing loss in children receiving cisplatin chemotherapy. Nat. Genet. 41 (12), 1345-1349. doi: 10.1038/ng.478

Ruiz-Pinto, S., Pita, G., Patiño-García, A., Alonso, J., Pérez-Martínez, A., Cartón, A. J., et al. (2017). Exome array analysis identifies GPR35 as a novel susceptibility gene for anthracycline-induced cardiotoxicity in childhood cancer. Pharmacogenet. Genomics 27 (12), 445-453. doi: 10.1097/FPC.000 0000000000309

Schaeffeler, E., Jaeger, S., Klumpp, V., Yang, J., Igel, S., Hinze, L., et al. (2019). Variants in nudix hydrolase 15 (NUDT15) and their importance for thiopurine-related haematotoxicity in an European cohort. NaunynSchmiedeberg's Arch. Pharmacol. 392, S25. doi: 10.1038/s41436-019-0448-7

Siegel, R. L., Miller, K. D., and Jemal, A. (2019). Cancer statistics, 2019. CA Cancer J. Clin. 69 (1), 7-34. doi: 10.3322/caac.21551

Singh, P., Wang, X., Hageman, L., Chen, Y., Magdy, T., Landier, W., et al. (2020). Association of GSTM1 null variant with anthracycline-related cardiomyopathy after childhood cancer-A Children's Oncology Group ALTE03N1 report. Cancer 1-8. doi: 10.1002/cncr.32948

Skiles, J. L., Chiang, C., Li, C. H., Martin, S., Smith, E. L., Olbara, G., et al. (2018). CYP3A5 genotype and its impact on vincristine pharmacokinetics and development of neuropathy in Kenyan children with cancer. Pediatr. Blood Cancer 65 (3), 1-14. doi: 10.1002/pbc.26854

Smid, A., Karas-Kuzelicki, N., Jazbec, J., and Mlinaric-Rascan, I. (2016). PACSIN2 polymorphism is associated with thiopurine-induced hematological toxicity in children with acute lymphoblastic leukaemia undergoing maintenance therapy. Sci. Rep. 6, 30244. doi: 10.1038/srep30244

Soler, A. M., Olano, N., Mendez, Y., Lopes, A., Silveira, A., Dabezies, A., et al. (2018). TPMT and NUDT15 genes are both related to mercaptopurine intolerance in acute lymphoblastic leukaemia patients from Uruguay. $\mathrm{Br}$. J. Haematol. 181 (2), 252-255. doi: 10.1111/bjh.14532

Stewart, C. F., Panetta, J. C., O'Shaughnessy, M. A., Throm, S. L., Fraga, C. H., Owens, T., et al. (2007). UGT1A1 promoter genotype correlates with SN-38 pharmacokinetics, but not severe toxicity in patients receiving low-dose irinotecan. J. Clin. Oncol. Off. J. Am. Soc. Clin. Oncol. 25 (18), 2594-2600. doi: $10.1200 /$ JCO.2006.10.2301 
Tanaka, Y., Nakadate, H., Kondoh, K., Nakamura, K., Koh, K., and Manabe, A. (2018). Interaction between NUDT15 and ABCC4 variants enhances intolerability of 6-mercaptopurine in Japanese patients with childhood acute lymphoblastic leukemia. Pharmacogenom. J. 18 (2), 275-280. doi: 10.1038/ tpj.2017.12

Thiesen, S., Yin, P., Jorgensen, A. L., Zhang, J. E., Manzo, V., McEvoy, L., et al. (2017). TPMT, COMT and ACYP2 genetic variants in paediatric cancer patients with cisplatin-induced ototoxicity. Pharmacogenet. Genomics 27 (6), 213-222. doi: 10.1097/FPC.0000000000000281

Thorn, C. F., Oshiro, C., Marsh, S., Hernandez-Boussard, T., McLeod, H., Klein, T. E., et al. (2011). Doxorubicin pathways: pharmacodynamics and adverse effects. Pharmacogenet. Genomics 21 (7), 440-446. doi: 10.1097/ FPC.0b013e32833ffb56

Trubicka, J., Zemojtel, T., Hecht, J., Falana, K., Piekutowska-Abramczuk, D., Ploski, R., et al. (2017). The germline variants in DNA repair genes in pediatric medulloblastoma: a challenge for current therapeutic strategies. BMC Cancer 17 (1), 239. doi: 10.1186/s12885-017-3211-y

Tsujimoto, S., Yanagimachi, M., Tanoshima, R., Urayama, K. Y., Tanaka, F., Aida, N., et al. (2016). Influence of ADORA2A gene polymorphism on leukoencephalopathy risk in MTX-treated pediatric patients affected by hematological malignancies. Pediatr. Blood Cancer 63 (11), 1983-1989. doi: $10.1002 / \mathrm{pbc} .26090$

Turan, C., Kantar, M., Aktan, C., Kosova, B., Orman, M., Bilgen, C., et al. (2019). Cisplatin ototoxicity in children: risk factors and its relationship with polymorphisms of DNA repair genes ERCC1, ERCC2, and XRCC1. Cancer Chemother. Pharmacol. 84 (6), 1333-1338. doi: 10.1007/s00280019-03968-2

Tzvetkov, M. V., Behrens, G., O’Brien, V. P., Hohloch, K., Brockmöller, J., and Benöhr, P. (2011). Pharmacogenetic analyses of cisplatin-induced nephrotoxicity indicate a renoprotective effect of ERCC1 polymorphisms. Pharmacogenomics 12 (10), 1417-1427. doi: 10.2217/pgs.11.93

Umerez, M., Gutierrez-Camino, Á, Muñoz-Maldonado, C., Martin-Guerrero, I., and Garcia-Orad, A. (2017). MTHFR polymorphisms in childhood acute lymphoblastic leukemia: Influence on methotrexate therapy. Pharmacogenom. Personalized Med. 10, 69-78. doi: 10.2147/PGPM.S107047

van de Velde, M. E., Kaspers, G. L., Abbink, F. C. H., Wilhelm, A. J., Ket, J. C. F., and van den Berg, M. H. (2017). Vincristine-induced peripheral neuropathy in children with cancer: A systematic review. Crit. Rev. Oncol. 114, 114-130. doi: 10.1016/j.critrevonc.2017.04.004

van der Wouden, C. H., van Rhenen, M. H., Jama, W. O. M., Ingelman-Sundberg, M., Lauschke, V. M., Konta, L., et al. (2019). Development of the PGx-Passport: A Panel of Actionable Germline Genetic Variants for Pre-Emptive Pharmacogenetic Testing. Clin. Pharmacol. Ther. 106 (4), 866-873. doi: $10.1002 /$ cpt.1489

van Rossum, E. F. C., and Lamberts, S. W. J. (2004). Polymorphisms in the glucocorticoid receptor gene and their associations with metabolic parameters and body composition. Recent Prog. Horm. Res. 59, 333-357. doi: 10.1210/ rp.59.1.333

Veal, G. J., Cole, M., Chinnaswamy, G., Sludden, J., Jamieson, D., Errington, J., et al. (2016). Cyclophosphamide pharmacokinetics and pharmacogenetics in children with B-cell non-Hodgkin's lymphoma. Eur. J. Cancer (Oxford Engl. 1990) 55, 56-64. doi: 10.1016/j.ejca.2015.12.007

Verma, N., Kumar, K., Kaur, G., and Anand, S. (2007). L-asparaginase: a promising chemotherapeutic agent. Crit. Rev. Biotechnol. 27 (1), 45-62. doi: $10.1080 / 07388550601173926$

Vinka Alkaloid Pathway, P. (2020). PharmGKB (Accessed on December 23, 2019). Available from: https://www.pharmgkb.org/pathway/PA150981002.

Visscher, H., Ross, C. J., Rassekh, S. R., Barhdadi, A., Dubé, M. P., Al-Saloos, H., et al. (2012). Pharmacogenomic prediction of anthracycline-induced cardiotoxicity in children. J. Clin. Oncol. 30 (13), 1422-1428. doi: 10.1200/ JCO.2010.34.3467

Visscher, H., Ross, C. J., Rassekh, S. R., Sandor, G. S., Caron, H. N., van Dalen, E. C., et al. (2013). Validation of variants in SLC28A3 and UGT1A6 as genetic markers predictive of anthracycline-induced cardiotoxicity in children. Pediatr. Blood Cancer 60 (8), 1375-1381. doi: 10.1002/pbc.24505

Visscher, H., Rassekh, S. R., Sandor, G. S., Caron, H. N., van Dalen, E. C., Kremer, L. C., et al. (2015). Genetic variants in SLC22A17 and SLC22A7 are associated with anthracycline-induced cardiotoxicity in children. Pharmacogenomics 16 (10), 1065-1076. doi: 10.2217/pgs.15.61

Vos, H. I., Guchelaar, H. J., Gelderblom, H., De Bont, E. S. J. M., Kremer, L. C. M., Naber, A. M., et al. (2016). Replication of a genetic variant in ACYP2 associated with cisplatin-induced hearing loss in patients with osteosarcoma. Pharmacogenet. Genomics 26 (5), 243-247. doi: 10.1097/FPC.0000 000000000212

Wahlund, M., Nilsson, A., Kahlin, A. Z., Broliden, K., Myrberg, I. H., Appell, M. L., et al. (2020). The Role of TPMT, ITPA, and NUDT15 Variants during Mercaptopurine Treatment of Swedish Pediatric Patients with Acute Lymphoblastic Leukemia. J. Pediatr. 216, 150-7.e1. doi: 10.1016/ j.jpeds.2019.09.024

Wang, H., and Tompkins, L. M. (2008). CYP2B6: new insights into a historically overlooked cytochrome P450 isozyme. Curr. Drug Metab. 9 (7), 598-610. doi: $10.2174 / 138920008785821710$

Wang, X., Sun, C.-L., Quiñones-Lombraña, A., Singh, P., Landier, W., Hageman, L., et al. (2016). CELF4 Variant and Anthracycline-Related Cardiomyopathy: A Children's Oncology Group Genome-Wide Association Study. J. Clin. Oncol. Off. J. Am. Soc. Clin. Oncol. 34 (8), 863-870. doi: 10.1200/JCO.2015.63.4550

Wang, S. M., Zeng, W. X., Wu, W. S., Sun, L. L., and Yan, D. (2018). Association between a microRNA binding site polymorphism in SLCO1A2 and the risk of delayed methotrexate elimination in Chinese children with acute lymphoblastic leukemia. Leuk. Res. 65, 61-66. doi: 10.1016/j.leukres.2018.01.004

Wheeler, H. E., Gamazon, E. R., Frisina, R. D., Perez-Cervantes, C., El Charif, O., Mapes, B., et al. (2017). Variants in WFS1 and Other Mendelian Deafness Genes Are Associated with Cisplatin-Associated Ototoxicity. Clin. Cancer Res. Off. J. Am. Assoc. Cancer Res. 23 (13), 3325-3333. doi: 10.1158/10780432.CCR-16-2809

Windsor, R. E., Strauss, S. J., Kallis, C., Wood, N. E., and Whelan, J. S. (2012). Germline genetic polymorphisms may influence chemotherapy response and disease outcome in osteosarcoma: a pilot study. Cancer 118 (7), 1856-1867. doi: $10.1002 / \mathrm{cncr} .26472$

Wolthers, B. O., Frandsen, T. L., Abrahamsson, J., Albertsen, B. K., Helt, L. R., Heyman, M., et al. (2017). Asparaginase-associated pancreatitis: A study on phenotype and genotype in the NOPHO ALL2008 protocol. Leukemia 31 (2), 325-332. doi: 10.1038/leu.2016.203

Wolthers, B. O., Frandsen, T. L., Patel, C. J., Abaji, R., Attarbaschi, A., Barzilai, S., et al. (2019). Trypsin-encoding PRSS1-PRSS2 variations influence the risk of asparaginase-associated pancreatitis in children with acute lymphoblastic leukemia: a Ponte di Legno toxicity working group report. Haematologica 104 (3), 556-563. doi: 10.3324/haematol.2018.199356

Wright, G. E. B., Amstutz, U., Drögemöller, B. I., Shih, J., Rassekh, S. R., Hayden, M. R., et al. (2019). Pharmacogenomics of Vincristine-Induced Peripheral Neuropathy Implicates Pharmacokinetic and Inherited Neuropathy Genes. Clin. Pharmacol. Ther. 105 (2), 402-410. doi: 10.1002/cpt.1179

Xu, H., Robinson, G. W., Huang, J., Lim, J. Y.-S., Zhang, H., Bass, J. K., et al. (2015). Common variants in ACYP2 influence susceptibility to cisplatininduced hearing loss. Nat. Genet. 47 (3), 263-266. doi: 10.1038/ng.3217

Yao, P., He, X., Zhang, R., Tong, R., and Xiao, H. (2019). The influence of MTHFR genetic polymorphisms on adverse reactions after methotrexate in patients with hematological malignancies: a meta-analysis. Hematology 24 (1), 10-19. doi: 10.1080/10245332.2018.1500750

Yousef, A. M., Farhad, R., Alshamaseen, D., Alsheikh, A., Zawiah, M., and Kadi, T. (2019). Folate pathway genetic polymorphisms modulate methotrexateinduced toxicity in childhood acute lymphoblastic leukemia. Cancer Chemother. Pharmacol. 83 (4), 755-762. doi: 10.1007/s00280-019-03776-8

Zgheib, N. K., Ghanem, K. M., Tamim, H., Aridi, C., Shahine, R., Tarek, N., et al. (2018). Genetic polymorphisms in candidate genes are not associated with increased vincristine-related peripheral neuropathy in Arab children treated for acute childhood leukemia: a single institution study. Pharmacogenet. Genomics 28 (8), 189-195. doi: 10.1097/FPC.0000000000000345

Zhang, D., Zhang, D., Cui, D., Gambardella, J., Ma, L., Barros, A., et al. (2007). Characterization of the UDP glucuronosyltransferase activity of human liver microsomes genotyped for the UGT1A1*28 polymorphism. Drug Metab. Disposition: Biol. Fate Chem. 35 (12), 2270-2280. doi: 10.1124/dmd.107.017806

Zhou, H., Li, L., Yang, P., Yang, L., Zheng, J. E., Zhou, Y., et al. (2018). Optimal predictor for 6-mercaptopurine intolerance in Chinese children with acute 
lymphoblastic leukemia: NUDT15, TPMT, or ITPA genetic variants? $B M C$ Cancer 18 (1), 516. doi: 10.1186/s12885-018-4398-2

Zhu, C., Liu, Y. W., Wang, S. Z., Li, X. L., Nie, X. L., Yu, X. T., et al. (2018). Associations between the C677T and A1298C polymorphisms of MTHFR and the toxicity of methotrexate in childhood malignancies: a meta-analysis. Pharmacogenom. J. 18 (3), 450-459. doi: 10.1038/tpj.2017.34

Zukunft, J., Lang, T., Richter, T., Hirsch-Ernst, K. I., Nussler, A. K., Klein, K., et al. (2005). A natural CYP2B6 TATA box polymorphism $(-82 \mathrm{~T}->\mathrm{C})$ leading to enhanced transcription and relocation of the transcriptional start site. Mol. Pharmacol. 67 (5), 1772-1782. doi: 10.1124/mol.104. 008086
Conflict of Interest: The authors declare that the research was conducted in the absence of any commercial or financial relationships that could be construed as a potential conflict of interest.

Copyright $\odot 2020$ Bernsen, Hagleitner, Kouwenberg and Hanff. This is an openaccess article distributed under the terms of the Creative Commons Attribution License (CC BY). The use, distribution or reproduction in other forums is permitted, provided the original author(s) and the copyright owner(s) are credited and that the original publication in this journal is cited, in accordance with accepted academic practice. No use, distribution or reproduction is permitted which does not comply with these terms. 